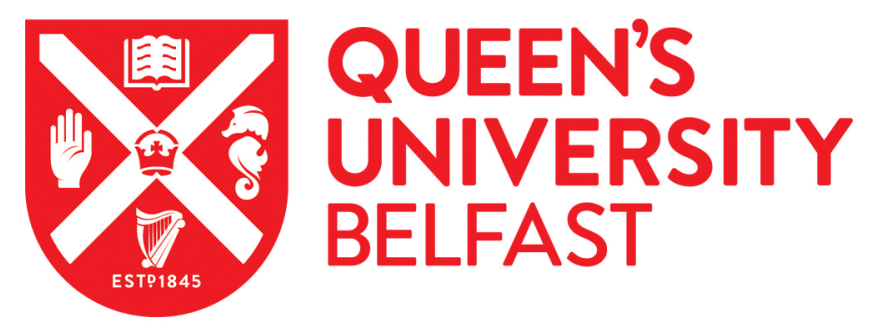

\title{
Multiplex bioimaging of proteins-related to neurodegenerative diseases in eye sections by laser ablation - Inductively coupled plasma - Mass spectrometry using metal nanoclusters as labels
}

Lores-Padín, A., Fernández, B., Álvarez, L., González-Iglesias, H., Lengyel, I., \& Pereiro, R. (2021). Multiplex bioimaging of proteins-related to neurodegenerative diseases in eye sections by laser ablation - Inductively coupled plasma - Mass spectrometry using metal nanoclusters as labels. Talanta, 221, [121489]. https://doi.org/10.1016/j.talanta.2020.121489

Published in:

Talanta

Document Version:

Peer reviewed version

Queen's University Belfast - Research Portal:

Link to publication record in Queen's University Belfast Research Portal

\section{Publisher rights}

(C) 2020 Elsevier B.V. All rights reserved.

This manuscript is distributed under a Creative Commons Attribution-NonCommercial-NoDerivs License

(https://creativecommons.org/licenses/by-nc-nd/4.0/), which permits distribution and reproduction for non-commercial purposes, provided the author and source are cited.

\section{General rights}

Copyright for the publications made accessible via the Queen's University Belfast Research Portal is retained by the author(s) and / or other copyright owners and it is a condition of accessing these publications that users recognise and abide by the legal requirements associated with these rights.

Take down policy

The Research Portal is Queen's institutional repository that provides access to Queen's research output. Every effort has been made to ensure that content in the Research Portal does not infringe any person's rights, or applicable UK laws. If you discover content in the

Research Portal that you believe breaches copyright or violates any law, please contact openaccess@qub.ac.uk. 


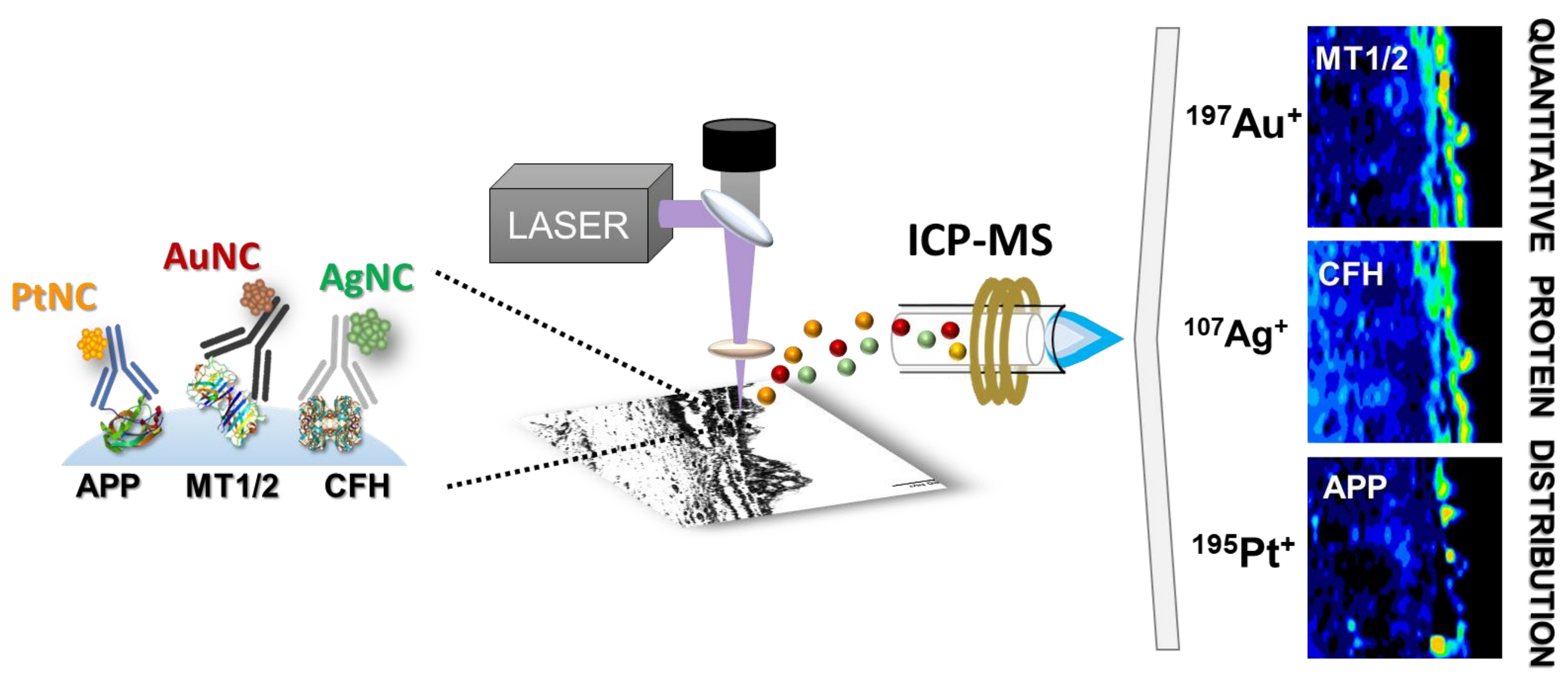




\title{
Quantitative multiplex bioimaging of proteins-related to neurodegenerative diseases in eye sections by laser ablation - inductively coupled plasma - mass spectrometry using metal nanoclusters as labels
}

\author{
Ana Lores-Padín ${ }^{1}$, Beatriz Fernández ${ }^{1,2 *}$, Lydia Álvarez ${ }^{2,3}$, Héctor González-Iglesias ${ }^{2,3 *}$, \\ Imre Lengyel $^{4}$, Rosario Pereiro ${ }^{1,2}$
}

${ }^{1}$ Department of Physical and Analytical Chemistry, University of Oviedo, Julian Clavería 8, 33006 Oviedo, Spain.

${ }^{2}$ Instituto Universitario Fernández-Vega, Fundación de Investigación Oftalmológica, Universidad de Oviedo, Oviedo, Spain.

3 Instituto Oftalmológico Fernández-Vega, Avda. Dres. Fernández-Vega, 34, 33012 Oviedo, Spain.

${ }^{4}$ Wellcome-Wolfson Institute for Experimental Medicine, School of Medicine, Dentistry and Biomedical Science, Queen's University Belfast, Belfast, Northern Ireland, United Kingdom.

*Authors to whom correspondence should be addressed:

fernandezbeatriz@uniovi.es \& h.gonzalez@fio.as 


\begin{abstract}
Simultaneous determination of proteins with micrometric resolution is a significant challenge. In this study, laser ablation (LA) inductively coupled plasma - mass spectrometry (ICP-MS) was employed to quantify the distribution of proteins associated to the eye disease age-related macular degeneration (AMD) using antibodies labelled with three different metal nanoclusters (MNCs). PtNCs, AuNCs and AgNCs contain hundreds of metal atoms and were used to detect metallothionein 1/2 (MT1/2), complement factor $\mathrm{H}(\mathrm{CFH})$ and amyloid precursor protein (APP) in retina, ciliary body, retinal pigment epithelium (RPE), choroid and sclera from human cadaveric eye sections. First, the labelling of MNCs bioconjugated primary antibodies ( $\mathrm{Ab}$ ) was optimised following an immunolabelling protocol to avoid the non-specific interaction of MNCs with the tissue. Then, the LA and ICP-MS conditions were studied to obtain high-resolution images for the simultaneous detection of the three labels at the same tissue section. A significant signal amplification was found when using AuNCs, AgNCs and PtNCs labelled Ab of 310, 723 and 1194 respectively. After the characterisation of MNCs labelled immunoprobes, the antibody labelling was used for quantitative determination of MT1/2, CFH and APP in the RPE-choroid-sclera, where accumulation of extracellular deposits related to AMD was observed, suggesting that this method is fully suitable for the simultaneous detection and quantification of at least three different proteins.
\end{abstract}

Keywords Metal nanoclusters. Quantitative bioimaging. Immunohistochemistry. Multiplex analysis of proteins. Age-related macular degeneration. Laser ablation ICPMS. 


\section{INTRODUCTION}

Age-related macular degeneration (AMD), a neurodegenerative eye disease, is the most common cause of irreversible visual loss in older people in developed countries [1]. AMD is characterised by progressive visual impairment due to degeneration of photoreceptors and the retinal pigment epithelium (RPE). Generally, AMD is classified into two clinical stages, early and late. The appearance of extracellular deposits between the RPE and the inner collagenous layer of Bruch's membrane and pigmentary abnormalities of the RPE are the main clinical signs of early AMD. Late AMD is characterised by neovascularisation (wet or exudative AMD) or geographic atrophy (known as nonneovascular, dry, or non-exudative AMD) [2].

New effective treatments exist for neovascular AMD (e.g., anti-vascular endothelial growth factor therapy [3]), whereas atrophic AMD still requires basic studies. It is known that atrophic AMD is related to the focal dysfunction of the RPE due to the growth of drusen, which results in photoreceptor death [4]. Several studies have identified lipids, proteins and minerals among the components inside these extracellular deposits [5-8]. The exploration of drusen formation and particularly their composition can help to understand not only their growth in the late stage of the disease but also will afford search for effective treatments to decrease its progress. Within this context, three proteins previously identified in drusen composition [8,9] will be investigated in this work: metallothionein $1 / 2(\mathrm{MT} 1 / 2)$, complement factor $\mathrm{H}(\mathrm{CFH})$ and $\beta$-amyloid precursor protein (APP).

Inductively coupled plasma - mass spectrometry (ICP-MS) offers interesting analytical capabilities, such as multi-elemental and isotopic determinations, limits of detection below $\mathrm{ng} \mathrm{mL}^{-1}$ and comparatively low matrix effects [10,11]. The use of specific probes labelled with exogeneous metal-tags makes possible the determination of selected biomolecules with high sensitivity and enormous multiplexing capabilities [12-14]. Additionally, the combination of metal-labelled immunoprobes with laser ablation (LA) - ICP-MS allows to detect the distribution of specific proteins within biological tissues with a micrometric resolution.

The most widely used method for the localisation of proteins is immunolabelling. Immunofluorescence provides increased sensitivity compared to colorimetric assays, and it is cheaper than LA-ICP-MS. Still, there are several limitations to use this method, such 
as difficulty to accomplish highly multiplexed assays because of dye bandwidth, troubles to measure simultaneously targets that differ in abundance by an order of magnitude or more, as well as risks of dye fluorescence quenching. Moreover, immunofluorescence procedures are limited by sample autofluorescence and signal scattering, and absolute quantification is difficult. These issues can be overcome by LA-ICP-MS analysis, constituting a promising alternative to conventional immunohistochemistry (IHC) and immunofluorescence $[15,16]$.

Several elemental (or isotopic) reporters have been proposed so far as labels for immunoprobes in LA-ICP-MS measurements. One of the strategies is the use of strong complexes formed by lanthanides with reagents which have additional reactive groups to bind to a recognition biomolecule. These have been effectively used, for example, for multiplex detection of three biomarkers of breast cancer tissue [17] and four proteins related to Parkinson disease [18]. Polymers containing several chelates of a given metal (or isotope) per label have also been employed to increase the number of reporter atoms per tag, allowing signal amplification $[14,19,20]$. This is an interesting strategy for the analysis of biomolecules in cells by liquid nebulisation ICP-MS [14,19] and LA-ICP-MS [20]. However, non-specific absorptions described in the analysis of biological tissues by LA-ICP-MS can limit the sensitivity of this method [21].

Higher signal enhancements can be obtained by using quasi-spherical metal nanoparticles as labels, with 5 to $50 \mathrm{~nm}$ diameters [22,23]. These nanoparticles contain thousands of metal atoms, but serious non-specific adsorptions have been described. The use of metal nanoclusters (MNCs) with diameters below $3 \mathrm{~nm}$, typically containing a few hundreds of metal atoms, offers lower risk of blocking recognition sites of the biomolecules [24], more efficient penetration within the biological tissue during the IHC procedure, as well as high amplification [25-27]. AuNCs and AgNCs have been successfully investigated for specific proteins bioimaging by LA-ICP-MS [25-27].

In this study we generated AuNCs, AgNCs and PtNCs labelled antibodies against MT1/2, $\mathrm{CFH}$ and APP. The quantitative distribution of the proteins in human eye sections was subsequently determined using home-made gelatine standards. Amplification properties of the selected MNCs, strategies to minimise non-specific absorption, as well as optimisation of LA-ICP-MS set-up to achieve the simultaneous analysis of three proteins along the same tissue section are among the parameters evaluated. 


\section{EXPERIMENTAL SECTION}

\subsection{Reagents and materials}

The one-pot syntheses of the water soluble MNCs were individually carried out using $\mathrm{H}_{2} \mathrm{PtCl}_{6}$ (8\% wt; Sigma-Aldrich, San Luis, USA), $\mathrm{AuCl}_{4} \mathrm{Na} \cdot \mathrm{H}_{2} \mathrm{O}$ (99\% powder; SigmaAldrich) and $\mathrm{AgNO}_{3}$ (99.9\% crystalline; Alfa Aesar, Thermo Fisher, Kandel, Germany) as the metal salt precursors for PtNCs, AuNCs and AgNCs, respectively. Lipoic acid (>98\% powder; Across Organics, Geel, Belgium) was employed in all cases as the stabilising ligand and $\mathrm{NaBH}_{4}(98 \%$ powder, Sigma Aldrich) as the reductant. $\mathrm{NaOH}$ (Sigma-Aldrich) was used to help ligand solubilisation and to achieve the proper $\mathrm{pH}$ of each synthesis solution. Propan-2-ol (Fisher Scientific, Hampton, USA) was used for the synthesis of AuNCs.

The carbodiimide crosslinking reaction was followed to covalently bind the MNCs with the corresponding specific primary antibody (Ab). For such purpose, 1-ethyl-3-(3dimethylaminopropyl) carbodiimide (EDC) (98\% powder; Across Organics) and Nhydroxysuccinimide (NHS) (> 98\% powder; Sigma-Aldrich) were used. Furthermore, TRIS base (> 99\%; Sigma-Aldrich), ethylenediaminetetraacetic acid (EDTA) (Panreac AppliChem, Barcelona, Spain) and L-glutathione reduced (>98\%; Sigma-Aldrich) were employed in AgNCs labelling protocol. Mouse monoclonal anti-human MT1/2 Ab (antih-MT1/2) (Abcam, Cambridge, UK), rabbit polyclonal anti-human CFH Ab (anti-h-CFH) (Abcam) and rabbit polyclonal anti-human APP Ab KPI Domain (Merck Millipore, Darmstadt, Germany) were the primary antibodies used. Hydroxylamine hydrochloride ( $\geq 99 \%$ powder; Sigma-Aldrich) was added at the last step of the antibody labelling to reduce non-specific interactions. For the purification of the MNCs and the MNCs labelled immunoprobes (MNCs:anti-h-Ab), 3 and $100 \mathrm{kDa}$ pore size Amicon ultra centrifugal filter units (Merck Millipore) were respectively used.

For the characterisation of the labelled immunoprobe, quantification of the available $\mathrm{Ab}$ in the immunoprobe was carried out by a non-competitive direct ELISA immunoassay. Protein IgG standard from rabbit (University of Oviedo), secondary Ab labelled with peroxidase (HRP) against rabbit proteins (Sigma-Aldrich), TMB- $\mathrm{H}_{2} \mathrm{O}_{2}$ substrate (SigmaAldrich) and sulfuric acid (95-97\%, Merck Millipore) were used. Furthermore, for the characterisation of the metallic part of the labelled immunoprobe, hydrochloric acid (34$37 \%$, trace analysis; VWR chemicals, Radnor, PA, USA) and nitric acid (67-69\%, trace 
analysis; VWR chemicals) were used for the digestion of MNCs labelled immunoprobes prior to ICP-MS measurements. For LA-ICP-MS measurements, matrix-matched laboratory standards (spiked with $\mathrm{Pt}, \mathrm{Ag}$ and $\mathrm{Au}$ ) were prepared using gelatine powder (VWR chemicals) for quantification purposes.

Human eyes were obtained $<24$ h post-mortem through the National Disease Research Interchange (Philadelphia, USA) and the Eye Depository at the UCL Institute of Ophthalmology (London, UK). In all cases eyes were formalin fixed and paraffin embedded (FFPE) following conventional protocols. The procedures adhered to the tenets of the Declaration of Helsinki. 5 and $10 \mu \mathrm{m}$ thick eye tissue sections (for immunofluorescence and LA-ICP-MS analyses, respectively) from the FFPE blocks were placed on poly-L-lysine surface coated microscope slides (Electron Microscopy Sciences, Hatfield, PA, USA). Sections were deparaffinised with xylene (Sigma-Aldrich) and dehydrated with absolute ethanol (VWR Chemicals). During the IHC stage, several reagents were used: ammonium chloride (Panreac) to minimise tissue autofluorescence (only in the immunofluorescence validation procedure), triton X-100 (Sigma-Aldrich) to permeabilise tissue sections, bovine serum albumin (BSA) (99\% powder, Merck) and goat serum (Sigma-Aldrich) to block non-specific interactions, and 4'6-diamidino-2phenylindole dihydrochloride (DAPI) (Thermo Fisher Scientific) to stain cell nuclei. Washing steps were carried out with phosphate-buffered saline (10 mM PBS - $0.9 \% \mathrm{NaCl}$, pH 7.4) (Sigma-Aldrich) and surfactant tween 20 (Sigma-Aldrich). Mounting media for fluorescence detection (Agilent Technologies, Santa Clara, CA, USA) was employed to protect the tissue and maintain the fluorescence signal during microscopy visualisation. Either Alexa Fluor Plus (A32740) consisting on Alexa® 594:goat anti-rabbit IgG or Alexa Fluor Plus (A32742) consisting on Alexa® 594:goat anti-mouse IgG, both from Thermo Fisher, were used as the secondary $A b$ for indirect immunoassays in the validation procedures.

Deionised ultrapure water, resistivity $18.2 \mathrm{M} \Omega \cdot \mathrm{cm}$ (Purelab Flex 3\&4; ELGA-Veolia, High Wycombe, UK) was utilised throughout.

\subsection{Instrumentation}

LA-ICP-MS analyses were carried out using a LA system (LSX-213 from Teledyne Cetac Technologies, Omaha, USA) coupled to a double-focusing sector field ICP-MS (Element 
2, Thermo Fisher Scientific, Bremen, Germany) working at low mass resolution mode.

\subsection{Experimental Procedures}

\subsubsection{Synthesis of metal nanoclusters}

The syntheses of the three thiolated MNCs (PtNCs, AuNCs and AgNCs) were carried out following the protocols described elsewhere [26,29,30]. A similar bottom-up procedure was used in all cases: the metal precursor (salt of the metal with a high oxidation state) is dissolved in basic aqueous media (adjusted with a $\mathrm{NaOH}$ solution) and subsequently reduced by $\mathrm{NaBH}_{4}$ under the presence of the stabilising agent (lipoic acid). The molar ratios (metal:ligand:reductor) have been optimised for each type of MNCs (1:5:1 for PtNCs, 1:3:2 for AuNCs and 1:16:12 for AgNCs). After several hours under continuously stirring (at room temperature for PtNCs and AuNCs, and at $4^{\circ} \mathrm{C}$ for $\mathrm{AgNCs}$ ), the MNCs were purified by ultrafiltration using $3 \mathrm{kDa}$ pore size Amicon ultra centrifugal filter units. The NCs in the filter were restored to a volume equal to the initial one with a buffer solution (PBS for PtNCs and AuNCs, and TRIS-EDTA for AgNCs). Next, MNCs were 
characterised by fluorescence, HR-TEM and ICP-MS measurements. HR-TEM images showed in the three cases MNCs with a spherical metal nucleus and FCC crystal structure $[26,29,30]$. As described elsewhere $[26,29,30]$, the average particle size determined for each type of MNCs was: $1.5 \pm 0.6 \mathrm{~nm}$ for PtNCs, $2.20 \pm 0.04 \mathrm{~nm}$ for AuNCs, and $2.9 \pm$ $0.1 \mathrm{~nm}$ for AgNCs.

\subsubsection{Synthesis and characterisation of the MNCs labelled immunoprobes}

For our experiments, we selected three antibodies for MNCs labelling. The labelling of the specific primary Ab (anti-h-MT1/2, anti-h-CFH or anti-h-APP) was first performed with PtNCs as the elemental label to accomplish the individual bioimaging distribution of the proteins in three consecutive eye tissue sections from the same donor. The procedure was carried out following the carbodiimide chemistry, and it was previously optimised in terms of keeping the properties of both components (i.e., the recognition capabilities of the Ab and the fluorescence properties of the PtNCs) [29]. $198 \mu \mathrm{L}$ of PtNCs solution was mixed with $100 \mu \mathrm{L}$ of each primary $\mathrm{Ab}\left(10 \mu \mathrm{g} \mathrm{mL}^{-1}\right)$, keeping a 1:20 molar ratio Ab:PtNCs. Then, mechanical stirring was started, and carbodiimide crosslinking reagents were added (1:1500:1500 molar ratio of Ab:EDC:NHS). After $2 \mathrm{~h}$ under vortex stirring at room temperature, purification was performed by ultrafiltration (100 kDa pore size Amicon). To avoid non-specific interactions between the PtNCs and the biological tissues, a final step was required to block free carboxylic groups. For that purpose, a primary amine (hydroxylamine) was added to the purified labelled immunoprobes solutions with a molar ratio of 1:50 PtNCs:hydroxylamine. After $2 \mathrm{~h}$ stirring, the solutions were purified by ultrafiltration (using $100 \mathrm{kDa}$ pore size Amicon). The purified labelled immunoprobes (PtNCs:anti-h-MT1/2, PtNCs:anti-h-CFH and PtNCs:anti-h-APP) were stored separately in PBS buffer at $4{ }^{\circ} \mathrm{C}$.

For the multiplexed analysis of MT1/2, CFH and APP in the same tissue section, each Ab was labelled with a specific type of MNCs (AuNCs as labels of anti-h-MT1/2, AgNCs as labels of anti-h-CFH and PtNCs as labels of anti-h-APP) following a protocol similar to that reported above for PtNCs (Ab:MNCs molar ratios of 1:3 for AuNCs, 1:3 for AgNCs and 1:20 for PtNCs were employed). Concerning the blocking step with hydroxylamine, molar ratios of 1:50 were used for AuNCs and PtNCs, whereas 1:20 was used for AgNCs. 
Finally, the purified MNCs labelled immunoprobes solutions were added into the same Eppendorf tube and stored at $4{ }^{\circ} \mathrm{C}$ until further use.

In order to obtain the quantitative bioimaging of the proteins by LA-ICP-MS with MNCs as labels, labelled immunoprobes must be characterised to know their amplification factors. For such purpose, both the concentration of $\mathrm{Ab}$ available for recognition purposes and the concentration of reporter metal must be calculated. Thus, a similar procedure to that described by Cruz-Alonso et al. [26,31] for AuNCs was performed for the three MNCs. Two types of experiments were required. On the one hand, a direct ELISA with rabbit IgG protein standard (produced with a known concentration in the "Biotechnology Preparative" unit of the Scientific-Technical Services of the University of Oviedo) was used to determine the available concentration of $\mathrm{Ab}$ in the MNCs labelled immunoprobe. On the other hand, the labelled immunoprobes were digested with aqua regia ( $\mathrm{PtNCs}$, AuNCs) or nitric acid (AgNCs) during $20 \mathrm{~min}$ in an ultrasonic bath and then diluted in $2 \%$ nitric acid to determine the metal concentration per immunoprobe by ICP-MS analysis (conventional nebulisation).

\subsubsection{Immunoassay protocol with the MNCs labelled immunoprobes for the bioimaging of proteins in biological tissue sections by LA-ICP-MS}

Eye tissue sections (10 $\mu \mathrm{m}$ thick) from FFPE blocks were deposited on poly-L-lysinecoated microscope slides. The fixed tissues were immersed twice $(2 \times 5 \mathrm{~min})$ in xylol solution to remove the paraffin and then were rehydrated in a decreasing graded alcohol series $(100 \%, 95 \%, 80 \%, 70 \%, 0 \%)$ for 5 min per condition. After washing three times (10 min) with $10 \mathrm{mM} \mathrm{PBS} \mathrm{pH} \mathrm{7.4,} \mathrm{a} \mathrm{solution} \mathrm{of} 0.1 \%$ triton X-100 in PBS was added to the sections for tissue permeabilization $(5 \mathrm{~min})$. A further washing step with PBS was necessary and then the blocking agent solution $(0.1 \%$ BSA and $10 \%$ goat serum solution in $10 \mathrm{mM}$ PBS, pH 7.4) was added for $30 \mathrm{~min}$ at room temperature. Bioimaging of PtNCs labelled MT1/2, CFH and APP antibodies were independently evaluated on consecutive tissue sections following an overnight incubation at $4{ }^{\circ} \mathrm{C}$ into a humidified chamber. For multiplexed analysis, a mixture of purified labelled immunoprobes (AuNCs:anti-hMT1/2, AgNCs:anti-h-CFH and PtNCs:anti-h-APP) were added to the tissue section. To favour the removal of the non-reactants, several washing stages with PBS were performed. Labelled sections were stored at $-20{ }^{\circ} \mathrm{C}$ till the analysis by LA-ICP-MS. 


\subsubsection{Quantitative bioimaging of proteins in eye tissue sections by LA-ICP-MS}

For LA-ICP-MS analyses, LA and ICP-MS instruments were daily optimised. The ICPMS tuning was performed using a $1 \mathrm{ng} \mathrm{g}^{-1}$ multielemental solution in terms of maximum signal intensity and low oxide formation $\left(\mathrm{ThO}^{+} / \mathrm{Th}^{+}\right)$. Furthermore, LA-ICP-MS was tuned by the analysis of SRM NIST 612 for maximum signal intensity, good stability (relative standard deviation below $4 \%$ ), the ${ }^{238} \mathrm{U}^{+} / 232 \mathrm{Th}^{+}$ratio close to 1 and the $\mathrm{ThO}^{+} / \mathrm{Th}^{+}$ ratio below $0.2 \%$. For the imaging of the ocular tissues, experimental conditions were optimised to ensure a complete ablation of the total tissue thickness (multiple line by line scanning). The selected conditions are summarised in Table 1. Quantitative distribution of $\mathrm{Pt}, \mathrm{Au}$, and $\mathrm{Ag}$ in the tissue sections was obtained by LA-ICP-MS using laboratory gelatine standards. Metal-doped gelatines $(0-25 \mu \mathrm{g} \mathrm{g}-1$ of $\mathrm{Pt}, \mathrm{Au}$ and $\mathrm{Ag})$ were measured daily, before and after the imaging analysis of the eye tissue to compensate for drift effects of the LA-ICP-MS instrument as well as for quantification purposes. Detailed information regarding the preparation and characterisation of the standards is collected in ESM. Twodimensional images of the proteins' distribution (MT1/2, CFH and APP) along the eye structures were built using the software ImageJ-Fiji. For data treatment, the gas blank contribution was eliminated from the raw intensity signals to work with net intensities (counts per second, cps).

\section{RESULTS AND DISCUSSION}

\subsection{Optimisation of the bioconjugation and IHC procedures using PtNCs as labels}

In a previous publication describing the determination of IgE in human sera using PtNCs by conventional nebulisation ICP-MS [29], the molar ratio between the Ab and PtNCs was optimised. Such optimisation was performed to maximise the amount of metal per $\mathrm{Ab}$ to achieve high amplification for ICP-MS detection while keeping the recognition capabilities of the Ab. A 1:20 molar ratio of Ab:PtNCs was found to be optimal. To employ PtNCs (and MNCs in general) as labels for examining protein distribution in biological tissues, an additional step is necessary after the binding of the Ab to the MNCs in the preparation of the labelled immunoprobes to minimise non-specific interactions with tissues. Primary amines, such as hydroxylamine have been successfully proved to block carboxylic groups of AuNCs and AgNCs [26,27]. In the present work three molar 
ratios of PtNCs:hydroxylamine (1:100, 1:50 and 1:20) were evaluated for reducing nonspecific PtNCs:anti-h-APP binding in the eye sections (Fig. 1). Labelling was carried out on consecutive eye sections and the comparison included a tissue without blocking with the primary amine. Fig. 1 shows a LA-ICP-MS line profile for ${ }^{195} \mathrm{Pt}^{+}$(APP protein) along the different layers of the neurosensory retina using 1:50 and 1:20 molar ratios and without the blocking step (Fig. 1a, 1b and 1c, respectively). Overall, it was found that decreasing the molar ratio between PtNCs and the primary amine both the ${ }^{195} \mathrm{Pt}^{+}$signal intensity and the non-specific binding increased, resulting in an almost continuous ${ }^{195} \mathrm{Pt}^{+}$ profile where it was not possible to distinguish between the retinal layers (Fig. 1c). The results showed that 1:50 molar ratio was optimal for PtNCs:anti-h-APP labelled immunoprobe and this ratio was used for all further experiments with PtNCs.

\subsection{PtNCs as label for the individual bioimaging of proteins in eye tissues by LA- ICP-MS}

AuNCs and AgNCs have previously been investigated as metal labels for proteins detection in biological tissues using LA-ICP-MS. However, PtNCs as labels of immunoprobes have not yet been explored for such purpose. PtNCs:anti-h-MT1/2, PtNCs:anti-h-CFH and PtNCs:anti-h-APP immunoprobes were synthesised and used on three consecutive sections (control donor) to study the distribution of MT1/2, CFH and APP proteins. The neurosensory retina was selected for the study due to its highly organised structure but diverse cellular architecture, following the experimental conditions outlined in Table 1 (ICP-MS set-up denoted as single imaging). Fig. 2 shows the qualitative images obtained by LA-ICP-MS of the ${ }^{195} \mathrm{Pt}^{+}$signal for MT1/2, CFH and APP distribution (Fig. 2a, 2b and 2c, respectively). According to the microarray analysis of Fig. S1 (ESM), MT1/2 isoforms were highly expressed in the neurosensory retina, followed by APP, while the expression levels of $\mathrm{CFH}$ were lower.

As previously reported using AuNCs and AgNCs immunoprobes [25,27], MT1/2 (Fig. 2a) was distributed at the outer nuclear layer (ONL), the inner nuclear layer (INL) and the ganglion cells (GC), while they were not observed in the inner and outer plexiform layers (IPL or OPL, respectively). CFH and APP proteins were not previously analysed using MNCs labels and experimental results obtained by LA-ICP-MS showed that CFH was mainly localised in the ONL and the outer segment of photoreceptors (PR) as well as 
at the INL, with qualitative lower distribution in GC (Fig. 2b). The APP protein (Fig. 2c) GC, similarly to that observed for MT1/2 and APP. The absence of proteins expression in IPL and OPL must be cautiously considered, since some tissues losses cannot be ruled out during sample processing.

As mentioned above, the distribution obtained for MT1/2 by LA-ICP-MS was confirmed by comparison with results previously reported [25]. However, the proteins APP and CFH have not been studied using MNCs immunoprobes with LA-ICP-MS or fluorescence detection up to date. Therefore, immunolocalization of CFH and APP proteins obtained along the retinal layers by LA-ICP-MS was corroborated by conventional immunofluorescence using Alexa® Plus 594. Although fluorescence detection solely permits qualitative analysis, the proteins distribution along micrometres (and even submicrometres) structures of eye tissues can be easily identified. Fig. S2 (ESM) shows the microscopy images of CFH and APP obtained by conventional immunofluorescence (Fig. $\mathrm{S} 2 \mathrm{a}$ and $\mathrm{S} 2 \mathrm{~b}$, respectively) in consecutive tissue sections to those employed for LA-ICPMS analyses. A correlation in the localisation of both APP and CFH proteins along the neurosensory retinal layers was observed by LA-ICP-MS and immunofluorescence. However, according to our microarray data (Fig. S1), the observed lower expression levels of $\mathrm{CFH}$ in the neurosensory retina may indicate some unspecific Ab labelling which should be attributed to the particular Ab used as immunoprobe. To our knowledge, there is hardly any current literature covering the IHC localisation of $\mathrm{CFH}$ in the human retina. Abundant expression of $\mathrm{CFH}$ has been detected in human RPE, considered local source of $\mathrm{CFH}$ in the eye, and $\mathrm{CFH}$ protein was confirmed in the neurosensory retina by western blot [32]. Recently, Bhutto et al. [33] found negative staining for CFH in neural retina, although previous studies showed robust CFH expression in human photoreceptor inner and outer segments and in the ganglion cell layer [34]. Therefore, considering that the inherent limitation on $\mathrm{CFH} \mathrm{Ab}$ specificity cannot ruled out, future studies must address the use of additional antibodies to confirm these observations. However, the validation of the LA-ICP-MS analytical methodology is not compromised, since similar results were obtained using this particular Ab by immunofluorescence and by LA-ICP-MS. 


\subsection{Experimental conditions for multiplex bioimaging by LA-ICP-MS}

Next step was to optimise the experimental conditions for the simultaneous analysis of three proteins. For this, three different MNCs were used as labels: PtNCs, AgNCs and AuNCs. Different studies were required to obtain high-resolution images of the three proteins to be detected on the same section using the sequential mass analyser. Both the ICP-MS acquisition method and the LA conditions (e.g., sample temperature, repetition rate and scan speed) were optimised for such purpose.

Concerning ICP-MS parameters, the effect of sequential isotope acquisition (sector-field MS) for multiplex bioimaging was studied by comparing the images obtained for the analysis of MT1/2, CFH and APP in the same tissue region (i.e., ${ }^{197} \mathrm{Au},{ }^{107} \mathrm{Ag}$ and ${ }^{195} \mathrm{Pt}$ isotopes were monitored in the same ICP-MS method) to those obtained in three adjacent regions of the same section after the multiplex IHC protocol (i.e., three different ICP-MS methods were employed, monitoring a single isotope in each one). Fig. S3 (ESM) depicts the images obtained for MT1/2 $\left({ }^{197} \mathrm{Au}^{+}\right)$, CFH $\left({ }^{107} \mathrm{Ag}^{+}\right)$and APP $\left({ }^{195} \mathrm{Pt}^{+}\right)$distribution in the human neurosensory retina (control donor) using single and multiplex imaging LAICP-MS (Fig. S3a and S3b, respectively). As can be seen, the MT1/2, CFH and APP distribution can be distinguished in both cases, with preferential localisation in the INL, the ONL and the GC for MT1/2 and CFH, with a lesser extent in the INL and the GC for APP. However, the measurement of one single isotope per analysis (Fig. S3a) allows to reduce the acquisition time of the ICP-MS and, thus, the distribution of MT1/2, CFH and APP throughout the retinal layers can be discriminated with a better lateral resolution.

Another important aspect to be considered is the sample temperature during the LA sampling. Several authors [28,35-37] reported better resolved heteroatoms images for samples analysed at temperatures below $0{ }^{\circ} \mathrm{C}$ compared to those obtained at room temperature. A smaller heat affected region as well as less re-deposition into adjacent structures during the ablation was observed at low temperature. In the present work the use of cryogenic conditions $\left(-20^{\circ} \mathrm{C}\right)$ and room temperature $\left(25^{\circ} \mathrm{C}\right)$ were compared for the analysis of MT1/2, CFH and APP proteins at ciliary body. The pars plicata region was selected for sample temperature evaluation since the sinuous shape of the microstructure of these ciliary processes makes the selection of LA conditions critical to obtain well resolved images. First, the presence of MT1/2, CFH and APP in ciliary body structure was confirmed by conventional immunofluorescence done in consecutive tissue 
sections to those employed for LA-ICP-MS analyses. Fig. S4 (ESM) collects the images obtained for the three proteins distribution along ciliary processes.

LA-ICP-MS images of ciliary processes obtained using MNCs immunoprobes allowed to visualise MT1/2, CFH and APP distribution in the different cell structures of the pars plicata region (Fig. 3). Figs. 3a and 3b show, respectively, the images obtained for the proteins distribution along ciliary body, working under cryogenic conditions and at room temperature. Both cases showed that MT1/2, CFH and APP were mainly located in the ciliary epithelial cells, both non-pigmented ciliary epithelium (NPCE) and pigmented ciliary epithelium (PCE). However, the use of low temperatures offered better resolved images and MT1/2, CFH and APP were specifically identified at the NPCE and PCE cells (Fig. 3a). In contrast, a higher abnormal localisation was observed in the ciliary processes at room temperature (Fig. 3b). This fact can be attributed to a less tissue damage as well as less contamination from the neighbouring lines using low temperature. Additionally, a lower scan speed was studied to evaluate its influence on the spatial resolution. Fig. 3c shows the distribution of MT1/2, CFH and APP along ciliary processes using $2.5 \mu \mathrm{m} \mathrm{s}^{-1}$ (at low temperature). Although a better lateral resolution was achieved by decreasing to the half the scan speed, the sensitivity significantly decreased, making the identification of the sought proteins almost impossible in some regions (e.g., ciliary epithelium at the basal part of the ciliary process). Thus, $5 \mu \mathrm{m} \mathrm{s}^{-1}$ was selected for further LA-ICP-MS analyses.

\subsection{Multiplex quantitative bioimaging of MT1/2, CFH and APP proteins in human eye sections}

\subsubsection{Characterisation of PtNCs and AgNCs immunoprobes}

In order to obtain not only the distribution of the proteins along the structures of the eye tissues sections by LA-ICP-MS but also to compare signals of different proteins as well as to obtain the proteins concentration, it is necessary to determine the amplification provided by each MNCs labelled immunoprobes (the steps required for the metal immunoprobes characterisation can be followed in the schematic diagram of Fig. S5). To this end, the ratio between the metal detected by ICP-MS (i.e., Au, Ag, or Pt) and the selected antigen (e.g., MT1/2, CFH or APP) must be determined. Furthermore, the 
number of metal atoms linked to each available $\mathrm{Ab}(\mathrm{N})$ must be determined to know the

\subsubsection{Quantitative bioimaging of proteins-related to neurodegenerative diseases using MNCs labels by LA-ICP-MS}

$10 \mu \mathrm{m}$ thick cross-sections of human eyes from control and AMD post-mortem donors were ablated using experimental conditions collected in Table 1 (multiplex imaging). Two dimensional images of MT1/2, CFH and APP proteins covering an area of RPEchoroid-sclera region were simultaneously obtained from the same section by monitoring ${ }^{197} \mathrm{Au}^{+},{ }^{107} \mathrm{Ag}^{+}$and ${ }^{195} \mathrm{Pt}^{+}$from MNCs labelled immunoprobes. In contrast to traditional IHC and immunofluorescence procedures, MNCs labels combined to LA-ICP-MS allows to determine not only the qualitative distribution of the proteins $\left({ }^{197} \mathrm{Au}^{+},{ }^{107} \mathrm{Ag}^{+}\right.$and ${ }^{195} \mathrm{Pt}^{+}$ signals in cps) but also to compare the signal intensities and to know their concentration along the specific tissue structures. For this, $\mathrm{Au}, \mathrm{Ag}$ and $\mathrm{Pt}$ external calibration was carried out by using laboratory standards based on gelatines spiked with metals (standardsample bracketing calibration). A detailed description of the laboratory standards is collected at ESM. Furthermore, the flow diagram on Fig. S5 (ESM) illustrates the steps required to transform ${ }^{197} \mathrm{Au}^{+},{ }^{107} \mathrm{Ag}^{+}$and ${ }^{195} \mathrm{Pt}^{+}$intensity signals (MNCs) into MT1/2, CFH and APP concentrations.

The quantitative imaging of MT1/2, CFH and APP have been carried out in the RPEchoroid-sclera, where accumulation of extracellular deposits related to AMD may be present. Fig. 4 shows the quantitative images obtained from a post-mortem human donor without specific sub-RPE deposits characteristic of the macular disease (similar results were obtained with the microarray analysis, see Fig. S1). The simultaneous quantification of MT1/2, CFH and APP has been carried out, observing that MT1/2 was widely distributed in the sclera, and it was particularly concentrated at the RPE monolayer. The 
observed levels in the stroma of the choroid were lower, with some regions (matching the blood vessels) without MT1/2 (see Fig. 4a). The CFH protein was widely distributed and enriched in some parts of the RPE layer, showing similar concentration in the sclera region and lower levels in the stroma of the choroid. The APP was similarly distributed in the sclera and RPE region, but in a lesser extent compared to MT1/2 and CFH.

Additionally, this methodology has been used for the multiplexed quantitative bioimaging of MT1/2, APP and CFH in eye sections with AMD drusenoid deposits. In this case, prior to the LA-ICP-MS analysis of eye sections from post-mortem donors, transmission images were obtained by light microscopy to select specific region with sub-RPE deposits that had been show to contain a number of different proteins (Fig. S6 in the ESM). Drusen were observed between the RPE and the Bruch's membrane (marked with arrows and a square on Fig. S6).

Figs. 5 and 6 depict the quantitative imaging obtained by LA-ICP-MS for MT1/2, CFH and APP (\#1 and \#2 donors, respectively). As can be observed, the MT1/2 and CFH proteins were widely distributed along the RPE monolayer, with increased accumulation in sub-RPE deposits in specific hemispherical aggregates. Drusen deposits are marked with arrows in the images for a better localisation (the red arrow corresponds to the aggregates of deposits also observed in Fig. S6). The APP protein was conspicuously located in sub-RPE deposits. Overall, there is a preferential accumulation of selected proteins in subretinal drusenoid deposits. It should be noted that different scales from AMD and control tissues were fixed to properly observe the distribution of proteins in both cases. It must be highlighted that some differences observed on MT1/2, CFH and APP distribution and content along the eye structures can be attributed to biological diversity characteristics or disease severity for each individual patient.

\section{CONCLUSIONS}

An immunohistochemical method has been described to simultaneously localise and quantify in the same eye tissue section three proteins of interest in neurodegenerative diseases (such as AMD) using LA-ICP-MS. The multiplex methodology developed in this work allows the amplification of the protein detection due to the hundreds of metal atoms per tag (AuNCs, AgNCs and PtNCs). Moreover, knowing the number of tag atoms and available antibodies per labelled immunoprobe, quantification can be achieved. The 
multiplexed analysis by LA-ICP-MS showed a preferential accumulation of MT1/2, CFH and APP in sub-RPE drusenoid deposits in eyes from AMD post-mortem donors, although $\mathrm{Ab}$ specificity must be further considered (particularly for $\mathrm{CFH}$ ).

It must be noted that a sequential mass analyser was used. However, the use of the stateof-the-art ICP-MS instruments using a time of flight mass spectrometer would allow to increase the multiplexing capabilities using different MNCs labels. In any case, it should be stated that spatial resolution is not uniquely linked with the ICP-MS acquisition time since LA conditions as well as ablation chamber washout time have a critical effect on the spatial resolution obtained.

Finally, we would like to highlight that the combination of MNCs as labels of immunoprobes and LA-ICP-MS permitted the simultaneous localisation and quantification of three diverse proteins at the same time in an eye tissue whose autofluorescence limits the use of immunofluorescence-based techniques to detect protein distribution. In particular, in the current work the detection of MT1/2, CFH and APP was achieved in eye tissues including RPE and PCE, where the autofluorescence of these pigmented cells make difficult to visualise protein distribution by immunofluorescence.

\section{ACKNOWLEDGEMENTS}

This work was financially supported through project CTQ2016-79015-R by Agencia Estatal de Investigación (Spain) and FEDER. A. Lores-Padín and B. Fernández respectively acknowledge the FPU Grant (Ref. MECD-17-FPU16/01363; Ministry of Education) and the contract RYC-2014-14985 through the "Ramón y Cajal Program" (Ministry of Economy and Competitiveness). This research was also supported by a grant from the Belfast Association for the Blind and the "Eye-Risk" European Union's Horizon 2020 research and innovation program (grant ref.: 634479) (I.L). Tissue for this project was provided by the University College London Institute of Ophthalmology and Moorfields Eye Hospital Eye Tissue Repository supported by National Institute for Health Research funding. 
Table 1. Operating conditions of laser ablation and ICP-MS instruments for the analysis of proteins in ocular tissue sections by LA-ICP-MS using MNCs labelled immunoprobes.

\begin{tabular}{|c|c|c|}
\hline \multicolumn{3}{|c|}{ ICP-MS Element II (Thermo Fischer Scientifique) } \\
\hline Parameters & Single imaging & Multiplex imaging \\
\hline RF power & \multicolumn{2}{|c|}{$1350 \mathrm{~W}$} \\
\hline Cooling gas flow rate & \multicolumn{2}{|c|}{$16 \mathrm{~L} \cdot \mathrm{min}^{-1}$} \\
\hline Auxiliary gas flow rate & \multicolumn{2}{|c|}{$1.15 \mathrm{~L} \cdot \mathrm{min}^{-1}$} \\
\hline Nebuliser gas flow rate & \multicolumn{2}{|c|}{$0.7 \mathrm{~L} \cdot \mathrm{min}^{-1}$} \\
\hline Isotopes & ${ }^{107} \mathrm{Ag}$ or ${ }^{195} \mathrm{Pt}$ or ${ }^{197} \mathrm{Au}$ & ${ }^{107} \mathrm{Ag} \&{ }^{195} \mathrm{Pt} \&{ }^{197} \mathrm{Au}$ \\
\hline Sampling time & \multicolumn{2}{|c|}{$0.01 \mathrm{~s}$} \\
\hline Mass window & \multicolumn{2}{|c|}{75} \\
\hline Segment duration & $0.23 \mathrm{~s}$ & $1.74 \mathrm{~s}$ \\
\hline Measurements per peak & \multicolumn{2}{|c|}{30} \\
\hline Resolution mode & \multicolumn{2}{|c|}{ Low mass resolution } \\
\hline \multicolumn{3}{|c|}{ LA System LSX-213 (Teledyne Cetac Technologies) } \\
\hline Spot diameter & \multicolumn{2}{|c|}{$10 \mu \mathrm{m}$} \\
\hline Laser energy & \multicolumn{2}{|c|}{$\begin{array}{c}1.68 \mathrm{~mJ} \rightarrow \text { retina and } \mathrm{RPE} \\
2.4 \mathrm{~mJ} \rightarrow \text { ciliary body }\end{array}$} \\
\hline Scan speed & \multicolumn{2}{|c|}{$5 \mu \mathrm{m} \cdot \mathrm{s}^{-1}$} \\
\hline Repetition rate & \multicolumn{2}{|c|}{$20 \mathrm{~Hz}$} \\
\hline Ablation mode & \multicolumn{2}{|c|}{ Multi line scan } \\
\hline Carrier gas $(\mathrm{He})$ & \multicolumn{2}{|c|}{$1.0 \mathrm{~L} \cdot \mathrm{min}^{-1}$} \\
\hline Sample temperature & \multicolumn{2}{|c|}{$-20^{\circ} \mathrm{C}$} \\
\hline
\end{tabular}




\section{FIGURE LEGENDS}

Figure 1. ${ }^{195} \mathrm{Pt}^{+}$line profile obtained by LA-ICP-MS for the analysis of retinal layers in consecutive human eye tissue sections from a control donor after IHC protocol with PtNCs:anti-h-APP labelled immunoprobe using different PtNCs:hydroxylamine molar ratios. a) 1:50, b) 1:20; and c) without hydroxylamine. Width of the ablation lines at the ocular tissues range from $165 \mu \mathrm{m}$ to $285 \mu \mathrm{m}$. Retinal layers: ganglion cells (GC), inner nuclear layer (INL) and outer nuclear layer (ONL).

Figure 2. Analysis of proteins distribution along retinal layers in three consecutive human eye tissue sections from a control donor after IHC protocol with PtNCs labels by LAICP-MS. Column 1 shows the optical images of the analysed region obtained with the camera of the laser system. Column 2 depicts the ${ }^{195} \mathrm{Pt}^{+}$elemental image (intensity signal in cps) obtained by LA-ICP-MS using PtNCs labelled immunoprobes for individual detection of MT1/2, CFH, and APP proteins (14 LA lines). a) PtNCs:anti-h-MT1/2, (b) PtNCs:anti-h-CFH, and c) PtNCs:anti-h-APP.

Figure 3. Analysis of proteins distribution in adjacent pars plicata regions of the ciliary body from a human control donor after IHC protocol with MNCs labelled immunoprobes (AuNCs:anti-h-MT1/2, AgNCs:anti-h-CFH and PtNCs:anti-h-APP) by LA-ICP-MS. First column collects in all cases the optical image of the region analysed. a) Cryogenic conditions $\left(\mathrm{T}=-20{ }^{\circ} \mathrm{C}\right)$ and $5 \mu \mathrm{m} \mathrm{s}^{-1}$ scan speed, b) Room temperature $\left(\mathrm{T}=25^{\circ} \mathrm{C}\right)$ and 5 $\mu \mathrm{m} \mathrm{s}^{-1}$ scan speed, and c) Cryogenic conditions $\left(\mathrm{T}=-20{ }^{\circ} \mathrm{C}\right)$ and $2.5 \mu \mathrm{m} \mathrm{s}^{-1}$ scan speed. CS: ciliary stroma; PCE: pigmented ciliary epithelium; NPCE: non-pigmented ciliary epithelium. 
Figure 4. Quantitative bioimaging of MT1/2, CFH and APP proteins in the RPE region

Figure 5. Simultaneous quantitative bioimaging of MT1/2, CFH, and APP proteins in the RPE-choroid-sclera region of an AMD post-mortem donor (\#1) after simultaneous IHC protocol with MNCs labels (AuNCs:anti-h-MT1/2, AgNCs:anti-h-CFH, and PtNCs:antih-APP immunoprobes) by LA-ICP-MS (45 LA lines). a) Optical image of the region selected for LA-ICP-MS analysis taken by the camera of the LA system, b) MT1/2, c) $\mathrm{CFH}$, and d) APP. The protein specific localisation observed in drusen deposits are marked with arrows in the images.

Figure 6. Simultaneous quantitative bioimaging of MT1/2, CFH, and APP proteins in the RPE-choroid-sclera region of an AMD post-mortem donor (\#2) after simultaneous IHC protocol with MNCs labels (AuNCs:anti-h-MT1/2, AgNCs:anti-h-CFH, and PtNCs:antih-APP immunoprobes) by LA-ICP-MS (30 LA lines). a) Optical image of the region selected for LA-ICP-MS analysis taken by the camera of the LA system, b) MT1/2, c) $\mathrm{CFH}$, and d) APP. The protein specific localisation observed in drusen deposit is marked with an arrow in the image. 


\section{REFERENCES}

[1] W.L. Wong, X. Su, X. Li, C.M. Cheung, R. Klein, C.Y. Cheng, T.Y. Wong, Global prevalence of age-related macular degeneration and disease burden projection for 2020 and 2040: a systematic review and meta-analysis, Lancet Glob. Health 2 (2014) 106-116. [2] P. Mitchell, G. Liew, B. Gopinath, T.Y. Wong, Age-related macular degeneration, Lancet 392 (2018) 1147-1159.

[3] S.D. Solomon, K. Lindsley, S.S. Vedula, M.G. Krzystolik, B.S. Hawkins, Antivascular endothelial growth factor for neovascular age-related macular degeneration, Cochrane Database Syst. Rev. 3 (2019) CD005139. doi: 10.1002/14651858.CD005139.pub4.

[4] H. Al-Hussaini, M. Schneiders, P. Lundh, G. Jeffery, Drusen are associated with local and distant disruptions to human retinal pigment epithelium cells, Exp. Eye Res. 88 (2009) 610-612.

[5] C.A. Curcio, J. B. Presley, G. Malek, N.E. Medeiros, D.V. Avery, H.S. Kruth, Esterified and unesterified cholesterol in drusen and basal deposits of eyes with agerelated maculopathy, Exp. Eye Res. 81 (2005) 731-741.

[6] J.M. Flinn, P. Kakalec, R. Tappero, B. Jones, I. Lengyel, Correlations in distribution and concentration of calcium, copper and iron with zinc in isolated extracellular deposits associated with age-related macular degeneration, Metallomics 6 (2014) 1223-1228.

[7] A.C.S. Tan, M.G. Pilgrim, S. Fearn, S. Bertazzo, E. Tsolaki, A.P. Morrell, C. A. Curcio, Calcified nodules in retinal drusen are associated with disease progression in agerelated macular degeneration, Sci. Transl. Med. 10 (2018) eaat4544.

[8] J.W. Crabb, The proteomics of drusen, Cold Spring Harb. Perspect. Med. 4 (2014) a017194.

[9] R.B. Thompson, V. Reffatto, J.G. Bundy, E. Kortvely, J.M. Flinn, A. Lanzirotti, I. Lengyel, Identification of hydroxyapatite spherules provides new insight into subretinal pigment epithelial deposit formation in the aging eye, Proc. Natl. Acad. Sci. 112 (2015) $1565-1570$.

[10] A. Limbeck, P. Galler, M. Bonta, G. Bauer, W. Nischkauer, F. Vanhaecke, Recent advances in quantitative LA-ICP-MS analysis: challenges and solutions in the life sciences and environmental chemistry, Anal. Bioanal. Chem. 407 (2015) 6593-6617. 
[11] D. Pozebon, G.L. Scheffler, V.L. Dressler, Recent applications of laser ablation inductively coupled plasma mass spectrometry (LA-ICP-MS) for biological sample analysis: a follow-up review, J. Anal. At. Spectrom. 32 (2017) 890-919.

[12] C. Zhang, F. Wu, Y. Zhang, X. Wang, X. Zhang, A novel combination of immunoreaction and ICP-MS as a hyphenated technique for the determination of thyroidstimulating hormone (TSH) in human serum, J. Anal. At. Spectrom. 16 (2001) 13931396.

[13] T.C. de Bang, S. Husted, Lanthanide elements as labels for multiplexed and targeted analysis of proteins, DNA and RNA using inductively-coupled plasma mass spectrometry, Trends Anal. Chem. 72 (2015) 45-52.

[14] S.D. Tanner, V.I. Baranov, O.I. Ornatsky, D.R. Bandura, T.C. George, An introduction to mass cytometry: fundamentals and applications, Cancer Immunol. Immunother. 62 (2013) 955-965.

[15] D.P. Bishop, N. Cole, T. Zhang, P. A. Doble, D. J. Hare, A guide to integrating immunohistochemistry and chemical imaging, Chem. Soc. Rev. 47 (2018) 3770-3787.

[16] M. Cruz-Alonso, A. Lores-Padín, E. Valencia, H. González-Iglesias, B. Fernández, R. Pereiro, Quantitative mapping of specific proteins in biological tissues by laser ablation-ICP-MS using exogenous labels: aspects to be considered, Anal. Bioanal. Chem. 411 (2019) 549-558.

[17] C. Giesen, T. Mairinger, L. Khoury, L. Waentig, N. Jakubowski, U. Panne, Multiplexed immunohistochemical detection of tumor markers in breast cancer tissue using laser ablation inductively coupled plasma mass spectrometry, Anal. Chem. 83 (2011) 8177-8183.

[18] B. Neumann, S. Hösl, K. Schwab, F. Theuring, N. Jakubowski, Multiplex LA-ICPMS bio-imaging of brain tissue of a parkinsonian mouse model stained with metal-coded affinity-tagged antibodies and coated with indium-spiked commercial inks as internal standards, J. Neurosci. Methods 334 (2020) 108591.

[19] H.M. McGuire, T.M. Ashhurst (eds.), Mass cytometry: methods and protocols, Springer Nature 2019.

[20] Q. Chang, O.I. Ornatsky, I. Siddiqui, A. Loboda, V.I. Baranov, D.W. Hedley, Imaging mass cytometry, Cytometry Part A, 91A (2017) 160-169.

[21] L. Waentig, N. Jakubowski, S. Hardt, C. Scheler, P.H. Roos, M.W. Linscheidd, Comparison of different chelates for lanthanide labelling of antibodies and application in 
a Western blot immunoassay combined with detection by laser ablation (LA-)ICP-MS, J. Anal. At. Spectrom. 27 (2012) 1311-1320.

[22] M. Tvrdonova, M. Vlcnovska, L.P. Vanickova, V. Kanicky, V. Adam, L. Ascher, N. Jakubowski, M. Vaculovicova, T. Vaculovic, Gold nanoparticles as labels for immunochemical analysis using laser ablation inductively coupled plasma mass spectrometry, Anal. Bioanal. Chem. 411 (2019) 559-564.

[23] R. González de Vega, D. Clases, M.L. Fernández-Sánchez, N. Eiró, L.O. González, F.J. Vizoso, P.A. Doble, A. Sanz-Medel, MMP-11 as a biomarker for metastatic breast cancer by immunohistochemical-assisted imaging mass spectrometry, Anal. Bioanal. Chem. 411 (2019) 639-646.

[24] X-R. Song, H. Goswami, H-H. Yang, J. Xie, Functionalization of metal nanoclusters for biomedical applications, Analyst 141 (2016) 3126-3140.

[25] M. Cruz-Alonso, B. Fernandez, L. Álvarez, H. González-Iglesias, H. Traub, N. Jakubowski, R. Pereiro, Bioimaging of metallothioneins in ocular tissue sections by LAICP-MS using bioconjugated gold nanoclusters as specific tags, Microchim. Acta 185 (2018) 64.

[26] M. Cruz-Alonso, B. Fernandez, A. Navarro, S. Junceda, A. Astudillo, R. Pereiro, Laser ablation ICP-MS for simultaneous quantitative imaging of iron and ferroportin in hippocampus of human brain tissues with Alzheimer's disease, Talanta 197 (2019) 413421.

[27] E. Valencia, B. Fernández, M. Cruz-Alonso, M. García, H. González-Iglesias, M.T. Fernández-Abedul, R. Pereiro, Imaging of proteins in biological tissues by fluorescence microscopy and laser ablation-ICP-MS using natural and isotopically-enriched silver nanoclusters, J. Anal. At. Spectrom. (2020) Article in Press. https://doi.org/10.1039/C9JA00365G

[28] I. Konz, B. Fernández, M.L. Fernández, R. Pereiro, A. Sanz-Medel, Design and evaluation of a new Peltier-cooled laser ablation cell with on-sample temperature control, Anal. Chim. Acta 809 (2014) 88-96.

[29] A. Lores-Padín, M. Cruz-Alonso, H. González-Iglesias, B. Fernández, R. Pereiro, Bimodal determination of immunoglobulin E by fluorometry and ICP-MS by using platinum nanoclusters as a label in an immunoassay, Microchim. Acta 186 (2019) 705. [30] E. Valencia, M. Cruz-Alonso, L. Álvarez, H. González-Iglesias, B. Fernández, R. Pereiro, Fluorescent silver nanoclusters as antibody label in a competitive immunoassay for the complement factor H, Microchim. Acta 186 (2019) 429. 
[31] M. Cruz-Alonso, B. Fernandez, M. García, H. González-Iglesias, R. Pereiro, Quantitative imaging of specific proteins in the human retina by laser ablation ICPMS using bioconjugated metal nanoclusters as labels, Anal. Chem. 90 (2018) 12145-12151. [32] Md. Nawajes, A. Mandal, R. Ayyagari, Complement factor H: spatial and temporal expression and localization in the eye, Invest. Ophthalmol. Vis. Sci. 47 (2006) 40914097.

[33] I.A. Bhutto, T. Baba, C. Merges, V. Juriasinghani, D.S. McLeod, G.A. Lutty, Creactive protein and complement factor $\mathrm{H}$ in aged human eyes and eyes with age-related macular degeneration, Br. J. Ophthalmol. 95 (2011) 1323-1330.

[34] S.D. Martin, E. Bodek, L. Geng, S. Schaal, H.J. Kaplan, T.H. Tezel, Complement factor $\mathrm{H}(\mathrm{CFH})$ expression in mammalian retinal pigment epithelial cells, Invest. Ophthalmol. Vis. Sci. 49 (2008) 206.

[35] M. Zoriy, A. Matuch, T. Spruss, J.S. Becker, Laser ablation inductively coupled plasma mass spectrometry for imaging of copper, zinc and platinum in thin sections of a kidney from a mouse treated with cis-platin, Int. J. Mass Spectrom. 260 (2007) 102-106. [36] J.S. Hamilton, E.L. Gorishek, P.M. Mach, D. Sturtevant, M.L. Ladage, N. Suzuki, P.A. Padilla, R. Mittler, K.D. Chapman, G.F. Verbeck, Evaluation of a custom single Peltier-cooled ablation cell for elemental imaging of biological samples in laser ablation inductively coupled plasma-mass spectrometry (LA-ICP-MS), J. Anal. At. Spectrom. 31 (2016) 1030-1033.

[37] J.S. Becker, A. Matusch, C. Depboylu, J. Dobrowolska, M.V. Zoriy, Quantitative imaging of selenium, copper, and zinc in thin sections of biological tissues (slugs-genus arion) measured by laser ablation inductively coupled plasma mass spectrometry, Anal. Chem. 79 (2007) 6074-6080. 
a)

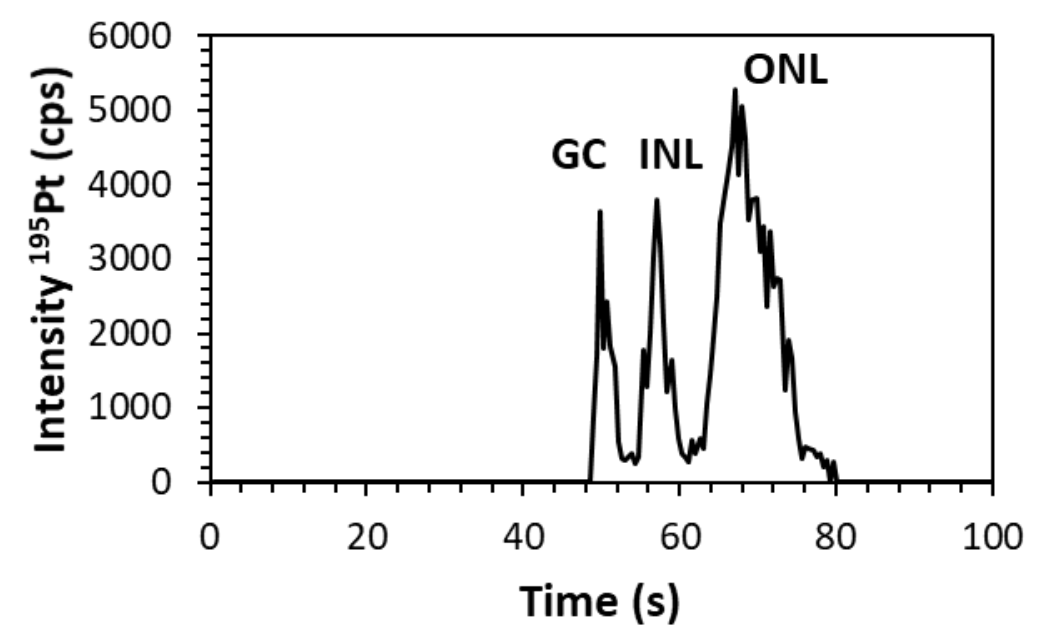

b)

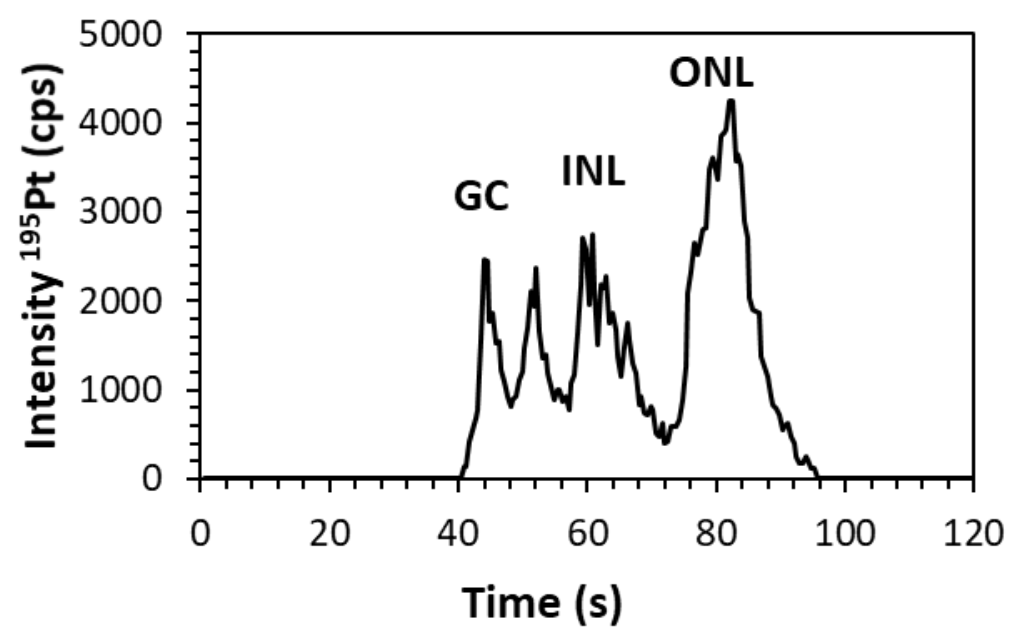

c)

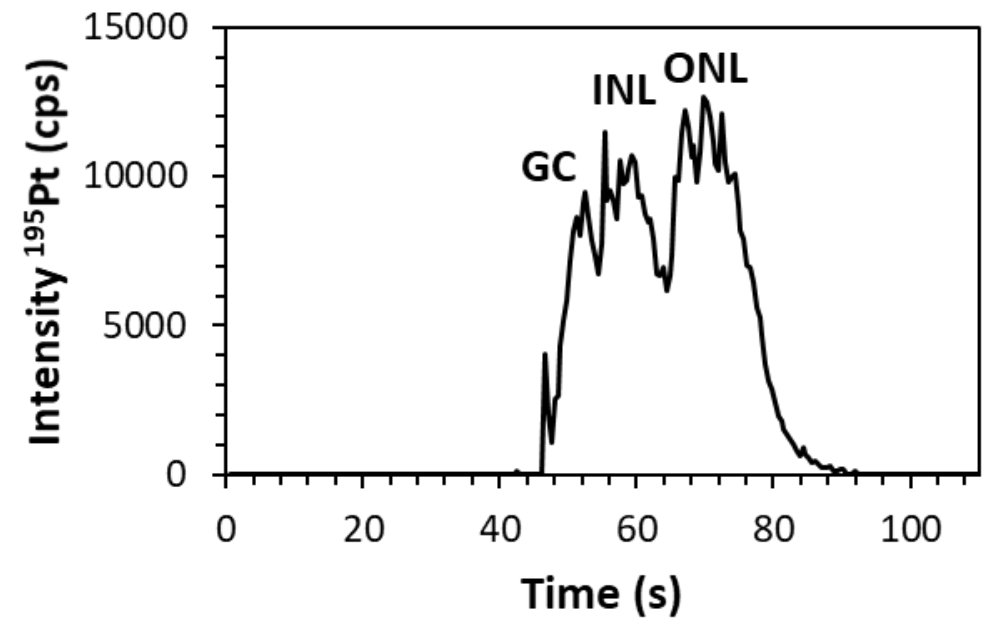

Figure 1 
a) 1
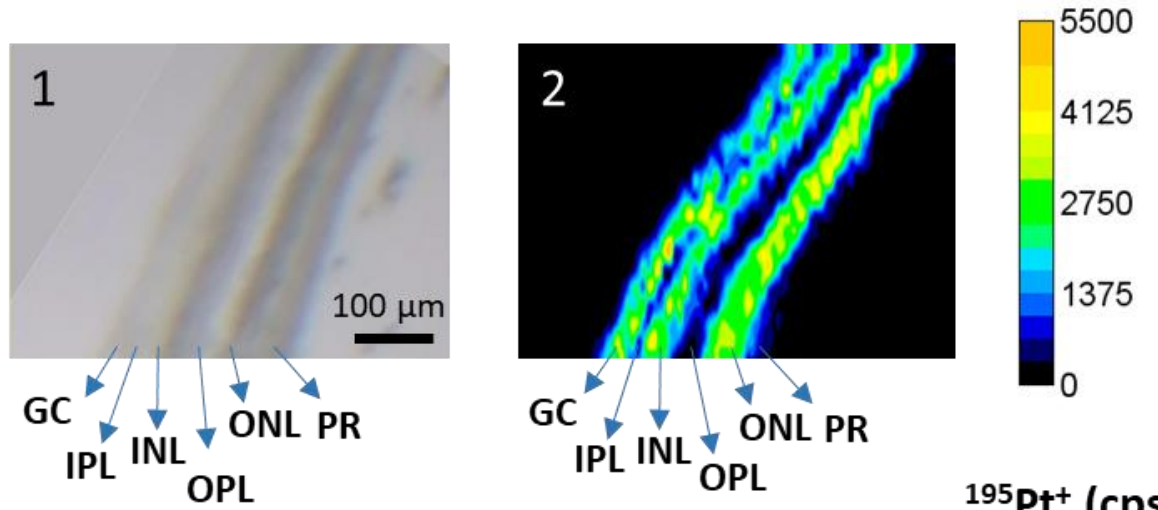

GC ONL PR OPL

${ }^{195} \mathrm{Pt}^{+}$(cps)

b)
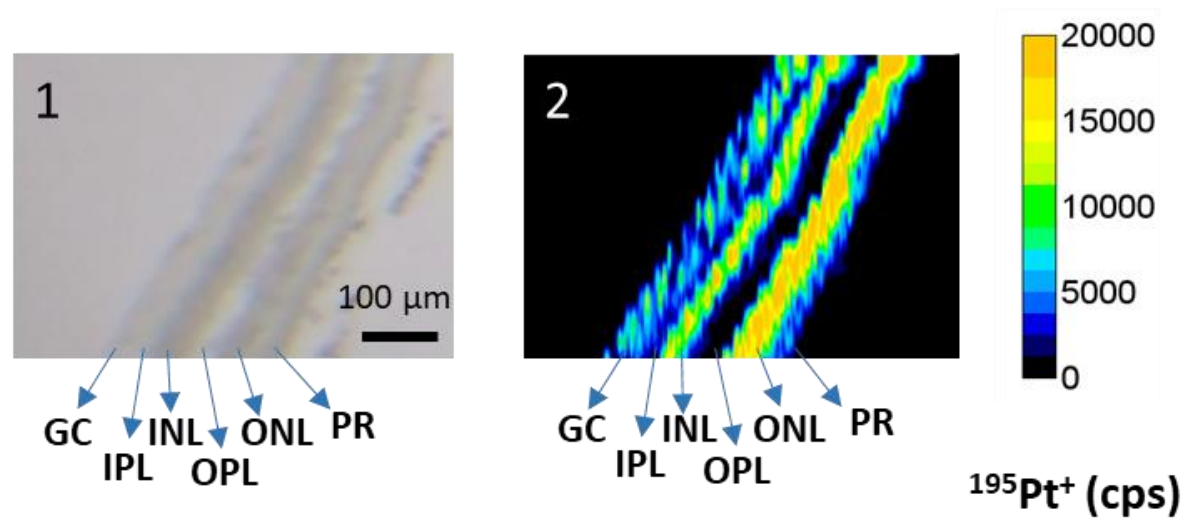

c)

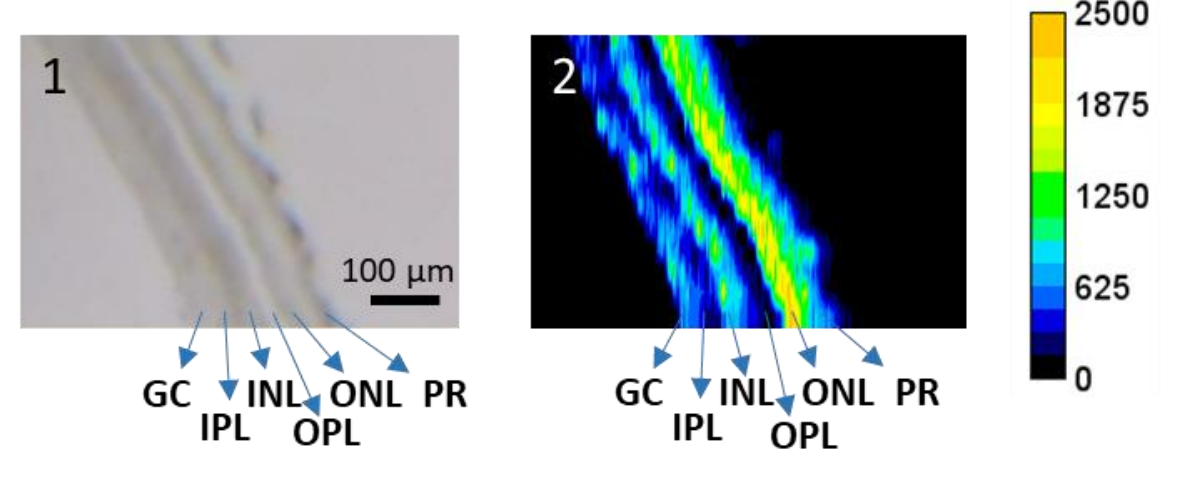

Figure 2 
$\mathrm{MT1} / 2\left({ }^{197} \mathrm{Au}^{+}\right)$

a)
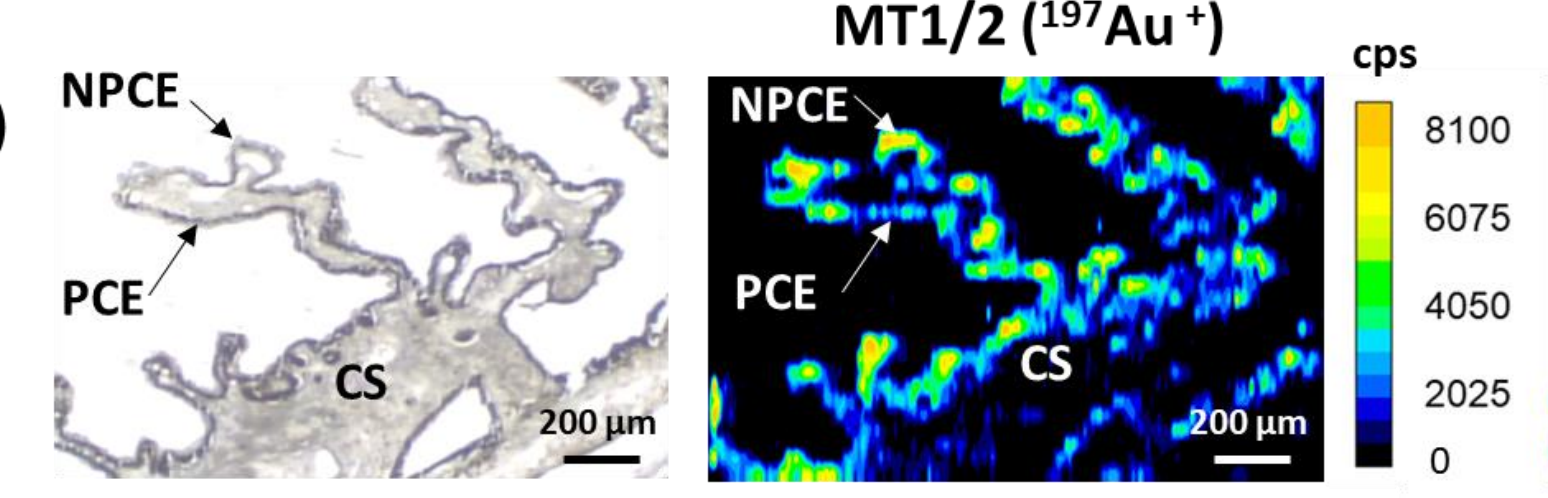

$\mathrm{CFH}\left({ }^{107} \mathrm{Ag}^{+}\right)$

b)

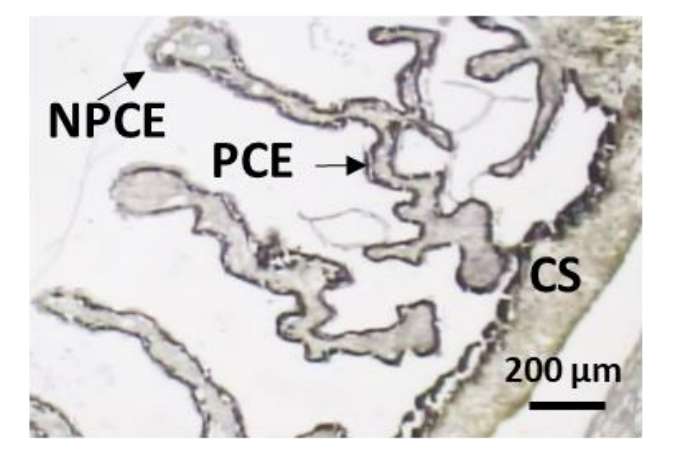

c)

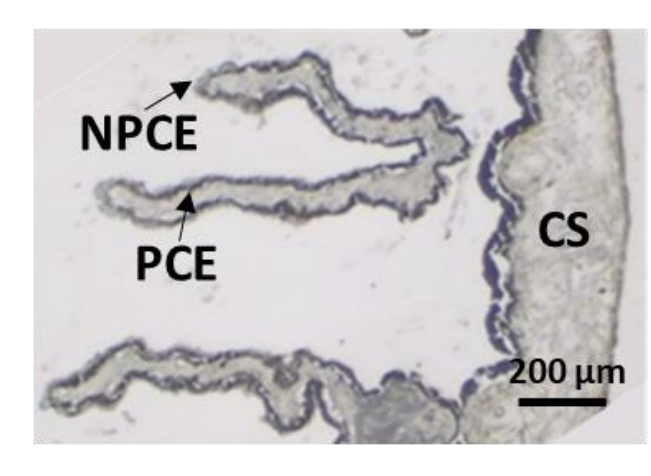

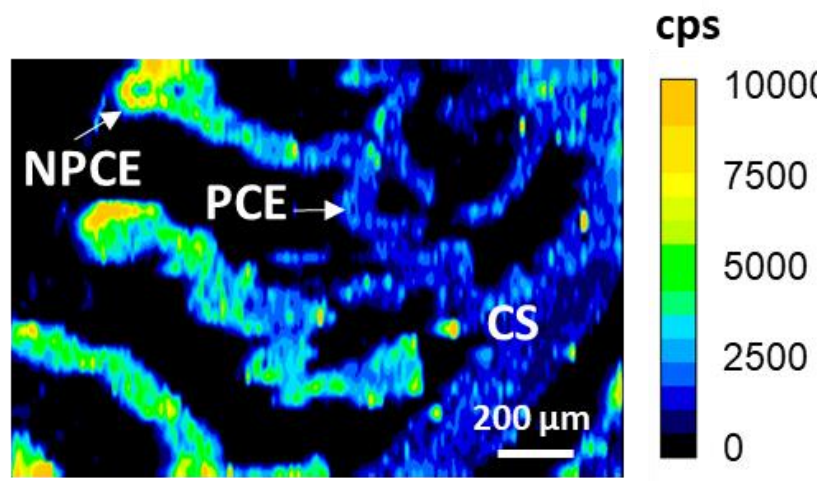

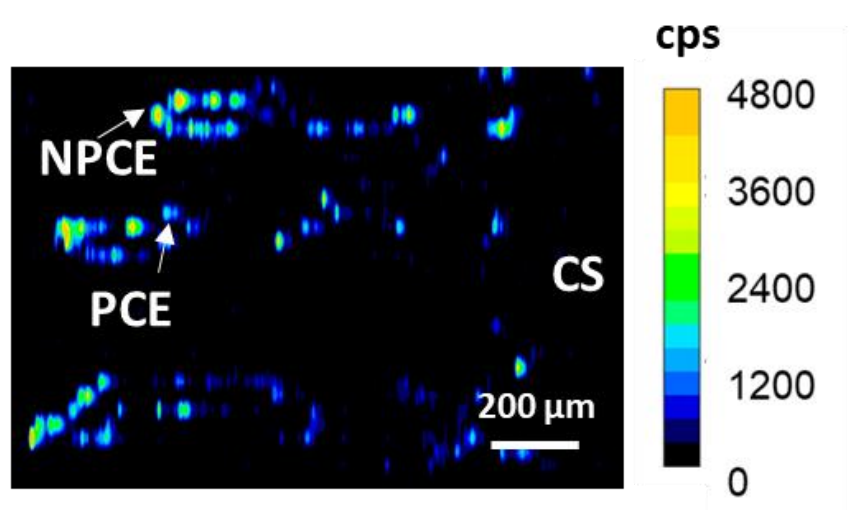

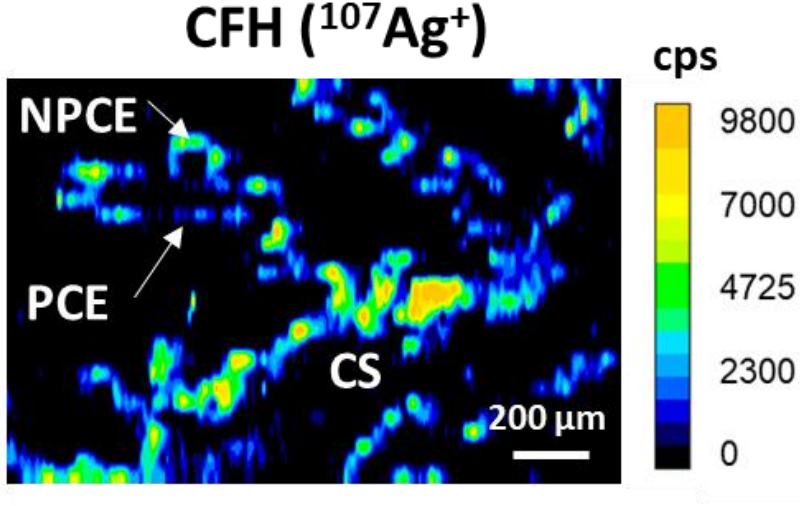

cps
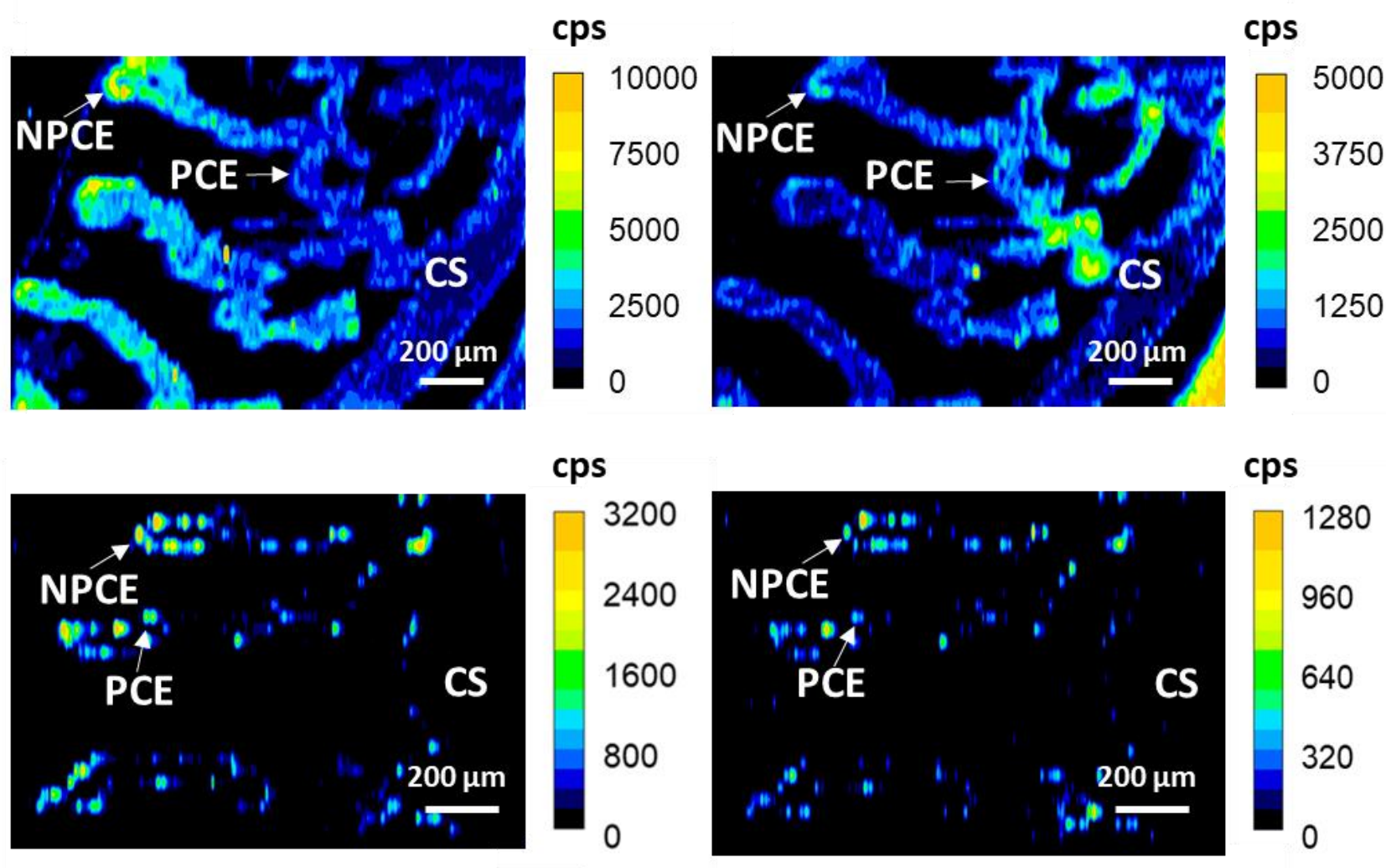

APP $\left({ }^{195} \mathrm{Pt}^{+}\right)$

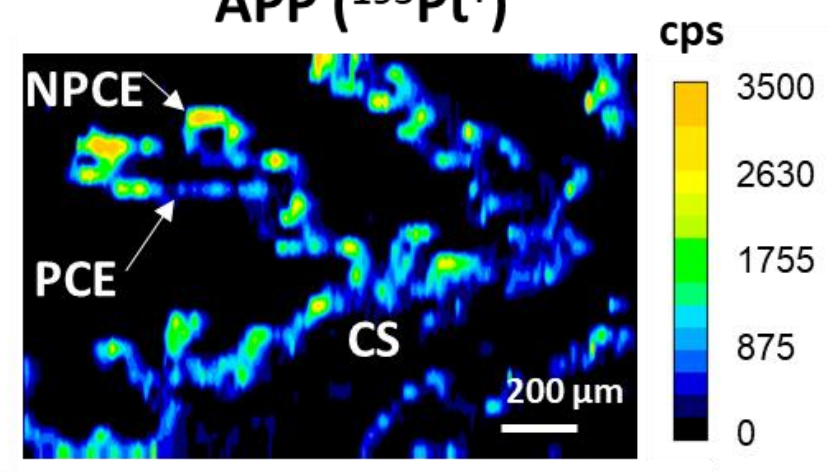

cps

5000

(750

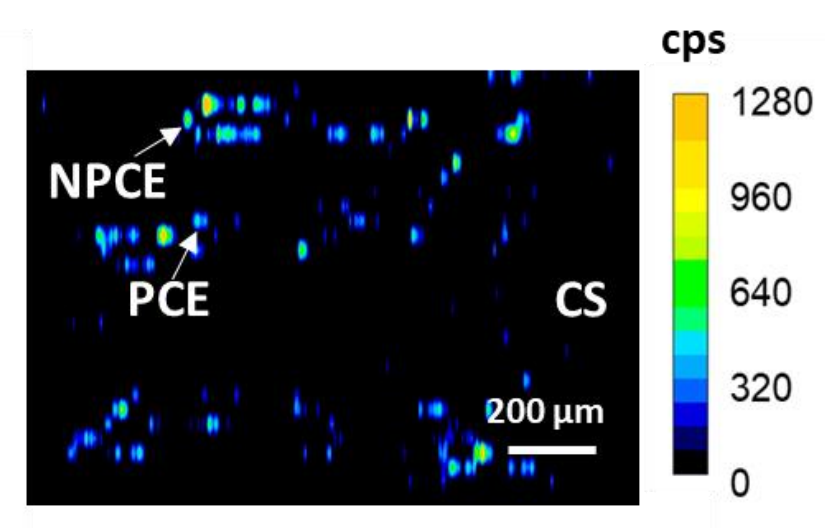

Figure 3 
a)

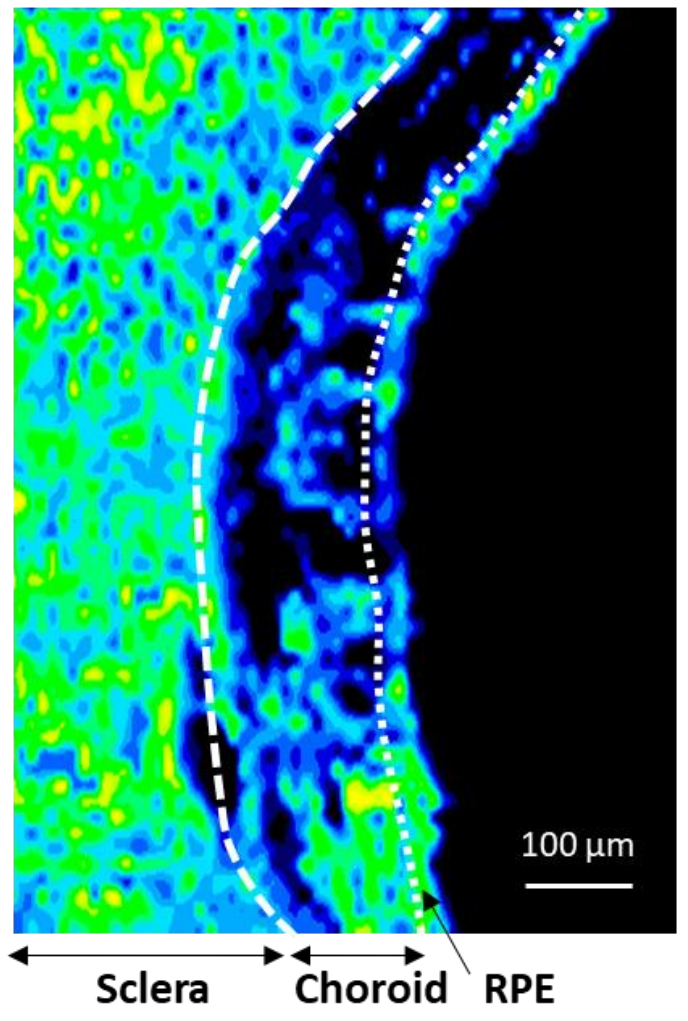

b)

MT1/2 (pmoles g ${ }^{-1}$ )

$\prod^{100.0}$

75.0

50.0

25.0

0.0

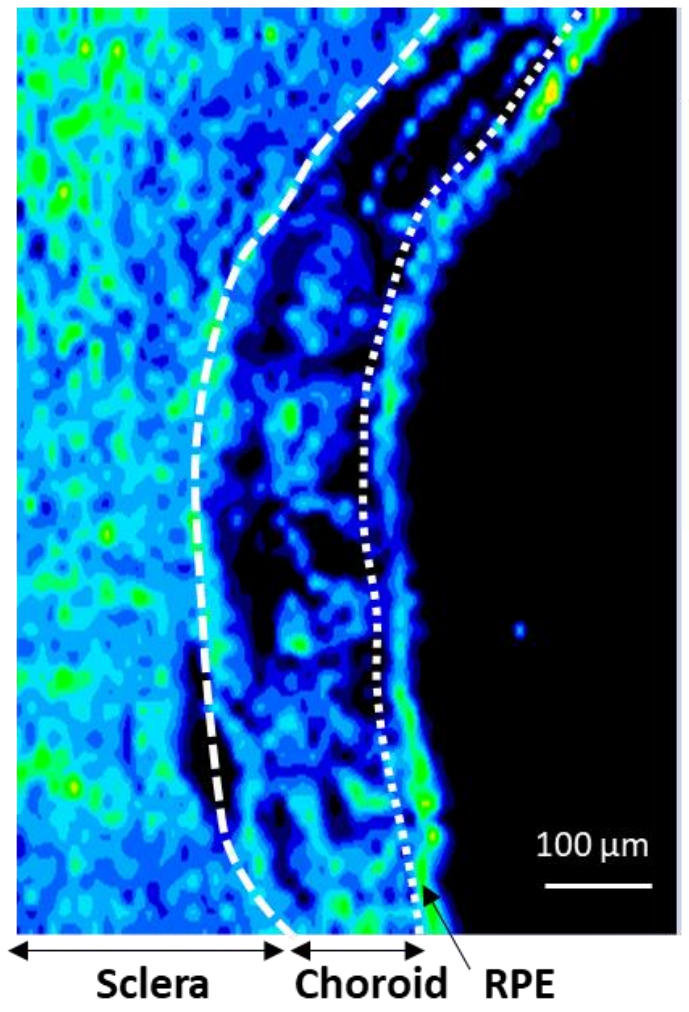

c)

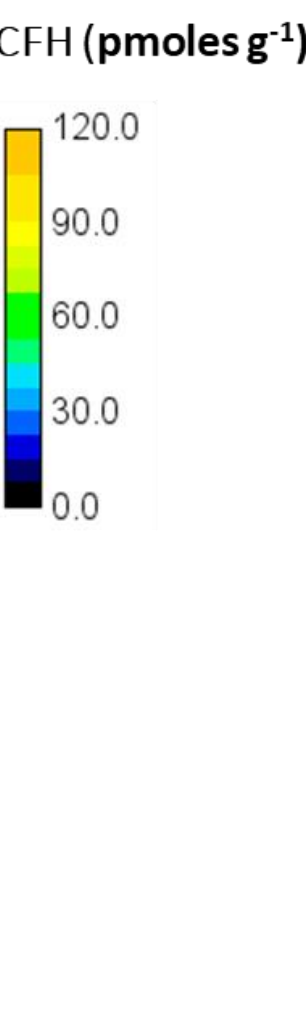

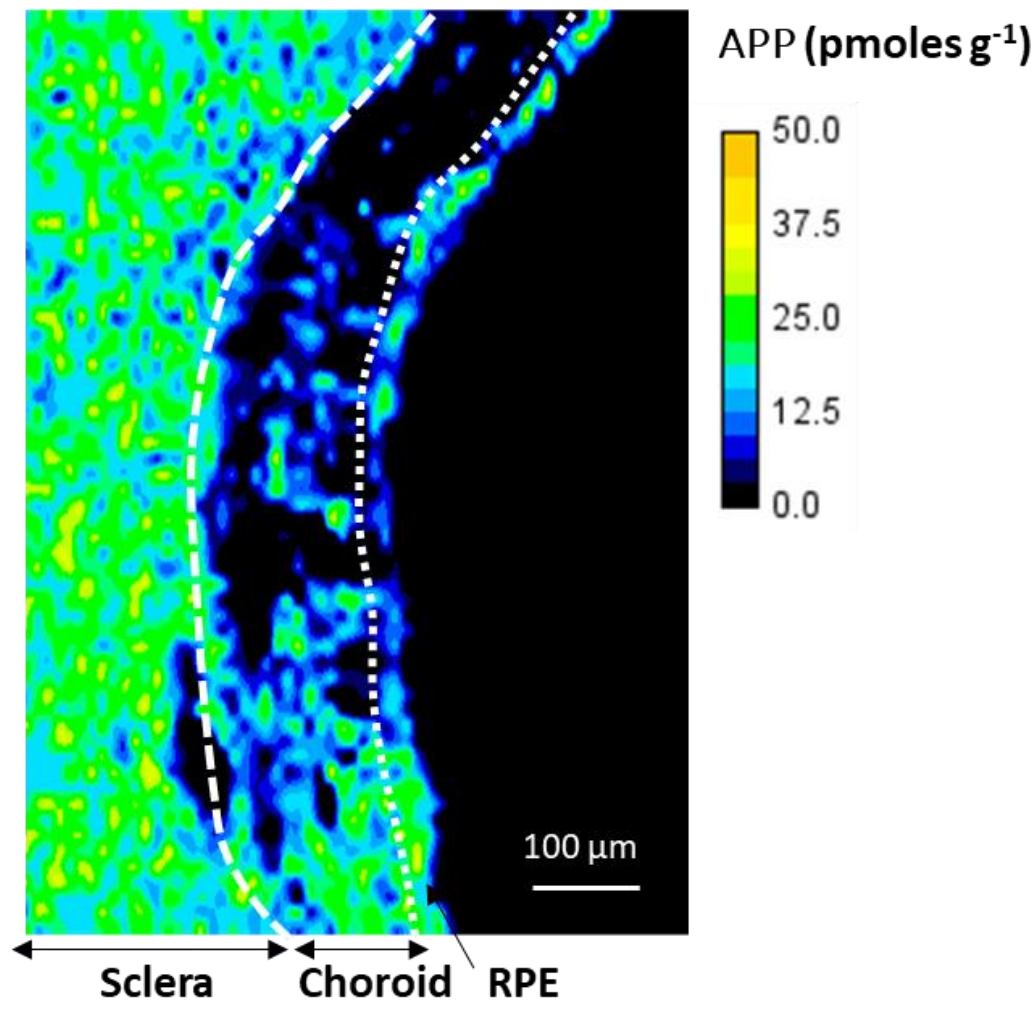

Figure 4 
a)

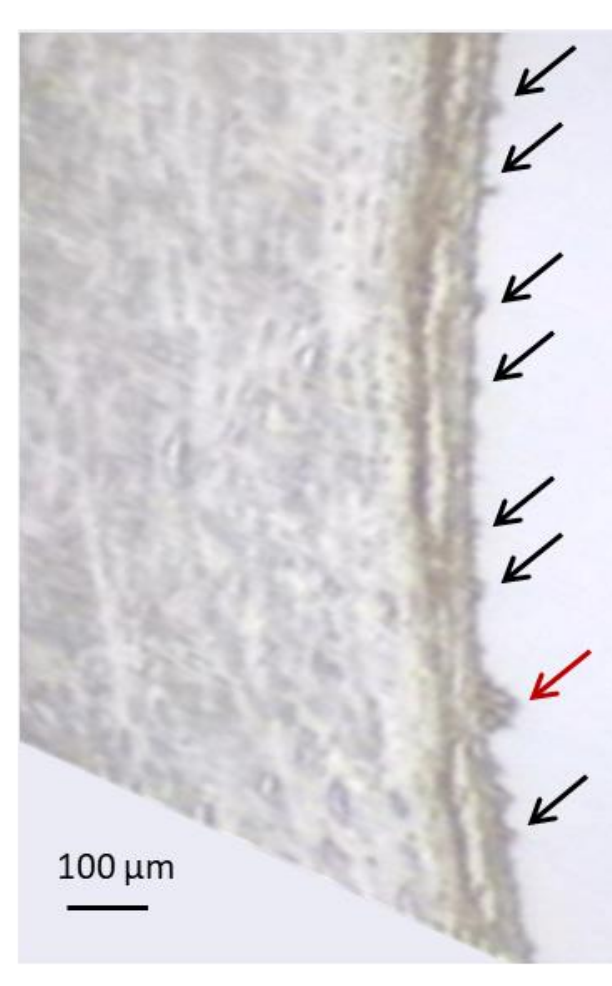

b)

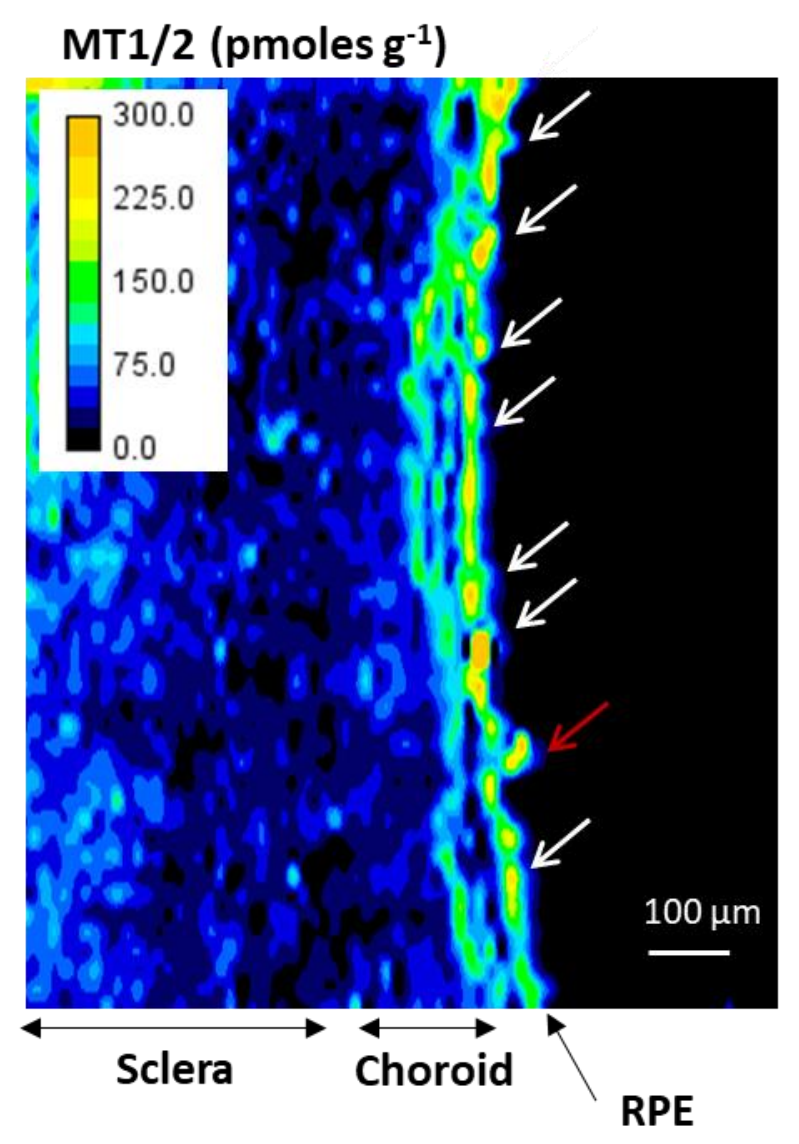

c)

CFH (pmoles g ${ }^{-1}$ )

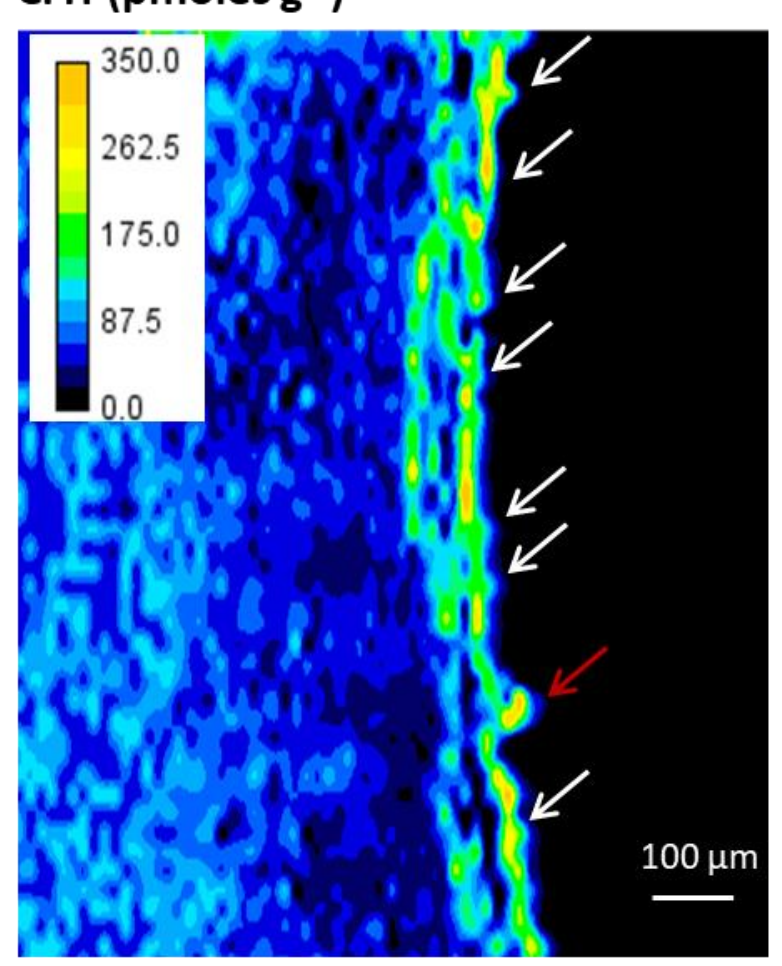

d)

APP (pmoles g g $^{-1}$ )

$\Gamma^{55.0} ! 1 / \swarrow$

41.2

27.5

13.8 0.0

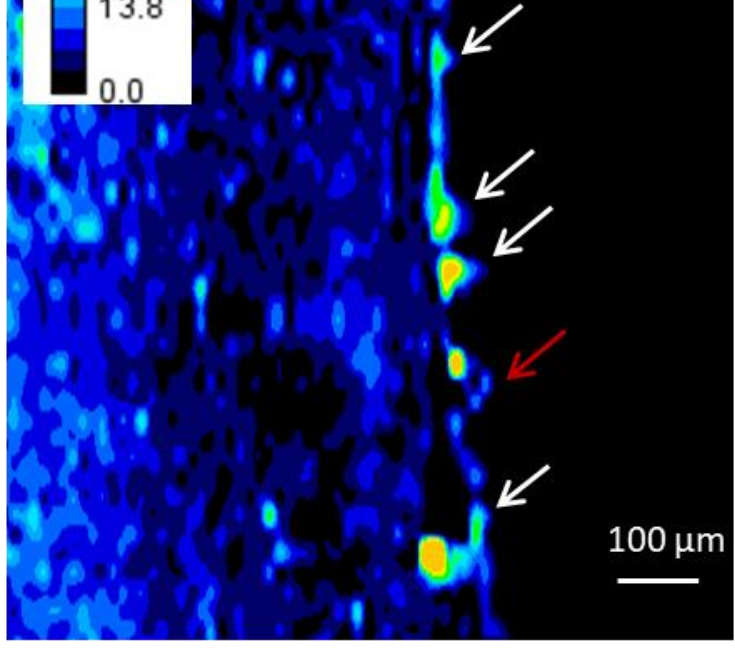

Figure 5 

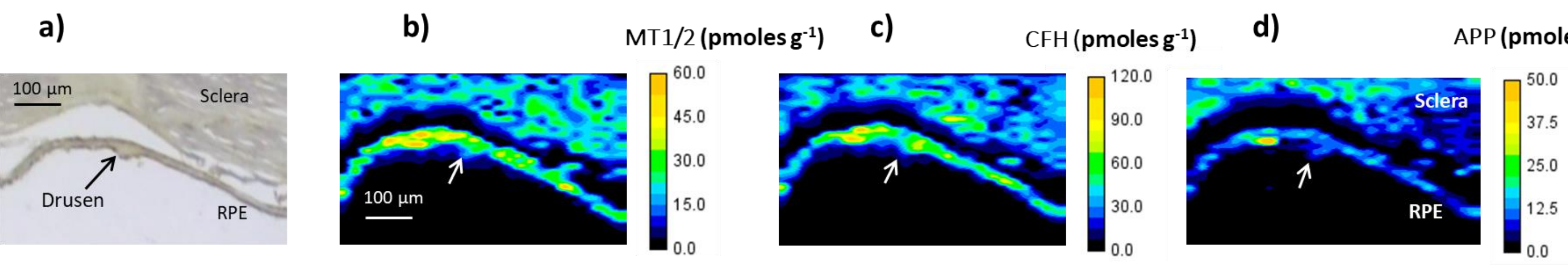

Figure 6 